\title{
Moxifloxacina: \\ profilo farmacologico, terapeutico e farmacoeconomico
}

PROFILO

Mario Eandi *

\begin{abstract}
Moxifloxacin is a new fluorquinolone antibiotic, recently introduced among the treatment options for upper and lower airways infections. It possesses a wide antibiotic spectrum, covering the major pathogens involved in the genesis of community acquired pneumonia (CAP), acute exacerbations of chronic bronchitis (AECB) and acute bacterial sinusitis (ABS). It acts in a concentration-dependent manner by inhibition of bacterial DNAgirase and topoisomerase IV, has a long biological half-life (about 12 hours), good oral bioavailability, excellent tissue diffusion and a better safety profile than other quinolones, because of the lack of phototoxicity and the scarsity of clinically significant drug interactions.

The clinical results of moxifloxacin in CAP, AECB and ABS have been compared with those of available alternative antibiotics in several multicentric, double-blind studies, and the new fluorquinolone resulted at least as effective as the comparators, with similar tolerability profiles. These studies demonstrated a high correlation among the eradication of the pathogen and the clinical recovery of the patients.

The pharmacodynamics, pharmacokinetics and clinical results of moxifloxacin render it one of the most attractive options for the empirical treatment of upper and lower airways infections, more so since its pharmacoeconomic profile appears to be very convenient. In fact, the low dosing frequency (once daily), the possibility of oral administration, the quick onset of the therapeutic action, the high clinical and microbiological success rate even with low duration cycles (5 days) and the good safety profile make the cost/efficacy ratio of moxifloxacin in the treatment of common airways infections very advantageous in comparison to those of all available treatment alternatives.
\end{abstract}

Farmeconomia e percorsi terapeutici 2003; 4 (2): 87-108

\section{PREMESSE}

Moxifloxacina è un nuovo fluorochinolone di recente introduzione nell' armamentario terapeutico per il trattamento antibiotico delle infezioni delle basse ed alte vie respiratorie [1-7].

Moxifloxacina è un 8-metossichinolone dotato di un ampio spettro d'azione antibatterico nei confronti dei batteri Grampositivi e Gram-negativi, aerobi ed anaerobi e dei patogeni atipici quali micoplasmi, legionelle e clamidie $[3,7,8]$. Questo nuovo antibiotico è tra i farmaci più potenti attualmente disponibili nei confronti dei batteri Gram-positivi, compresi lo Staphylococcus aureus meticillino-resistente e i pneumococchi, sia sensibili che resistenti alla penicillina. La moxifloxacina è attiva quanto la ciprofloxacina verso Legionella spp., ma più attiva verso Chlamydia spp. e Mycoplasma pneumoniae.
Moxifloxacina manifesta minore efficacia rispetto a ciprofloxacina verso le Enterobatteriaceae e verso Pseudomonas aeruginosa. Dotata di una potente e rapida azione battericida concentrazione-dipendente verso i batteri Gram-positivi e di un marcato effetto post-antibiotico, la moxifloxacina si accumula rapidamente nei ceppi sensibili, agisce inibendo in ugual misura sia la DNA girasi sia la topoisomerasi IV e manifesta una ridotta tendenza a selezionare ceppi mutanti resistenti $[1,7]$.

La farmacocinetica della moxifloxacina si caratterizza per la lunga emivita, circa 12 ore, per un'elevata biodisponibilità orale, un'eccellente diffusibilità tissutale extravascolare e per la scarsità di interazioni con altri farmaci $[1,7]$. Il profilo di tollerabilità, simile a quello dei fluorochinoloni, si differenzia, tuttavia, per l'assenza di fototossicità [2].
* Farmacologia Clinica Università di Torino 
Le proprietà microbiologiche della moxifloxacina hanno indirizzato il suo sviluppo clinico verso le infezioni delle vie respiratorie. Le sue caratteristiche microbiologiche, farmacocinetiche e farmacodinamiche e la dimostrata efficacia e tollerabilità clinica collocano la moxifloxacina tra i più interessanti antibiotici oggi disponibili per la terapia delle polmoniti acquisite in comunità (CAP), delle bronchiti croniche riacutizzate (AECB) e delle sinusiti batteriche acute (ABS) [2, 4-7].

In questo lavoro presentiamo un sintetico profilo farmacologico, clinico e terapeutico della moxifloxacina, avendo come obiettivo primario quello di evidenziare le relazioni tra le specifiche caratteristiche microbiologiche, farmacocinetiche e farmacodinamiche della molecola e le conseguenze sui costi sanitari e sociali dei pazienti affetti da infezioni delle vie respiratorie.

\section{CLASSIFICAZIONEDEI FLUOROCHINOLONI}

Storicamente i fluorochinoloni, analogamente ad altri farmaci, venivano classificati in generazioni, per indicare la successione con cui sono avvenute le varie modificazioni chimiche della molecola che hanno portato a nuovi prodotti farmaceutici. Questa classificazione, però, riveste unicamente un valore storico e non fornisce alcuna indicazione di utilità clinica.

Recentemente la Società Tedesca di Chemioterapia (PEG) ha proposto di classificare $\mathrm{i}$ fluorochinoloni attualmente in uso in quattro gruppi, utilizzando criteri microbiologici e terapeutici (Tabella 1) [6].

Nel gruppo $\mathrm{I}^{\circ}$ rientrano la norfloxacina e la pefloxacina, fluorochinoloni indicati soltanto per il trattamento delle infezioni del tratto urinario e per la profilassi e cura della diarrea del viaggiatore. $\mathrm{Nel}$ gruppo $\mathrm{II}^{\circ}$ sono compresi i classici fluorochinoloni ad ampio spettro ma con insufficiente attività nei confronti del pneumococco: la ciprofloxacina, leader di questo gruppo, e le altre tre molecole sono indicate soprattutto per le infezioni sostenute da batteri Gram-negativi, compresi i patogeni difficili come lo Pseudomonas aeruginosa, e sono quindi di notevole efficacia e utilità nel trattamento di molte infezioni sia comunitarie (dopo identificazione del germe responsabile) sia nosocomiali, comprese le polmoniti sostenute da Gram-negativi sensibili; non sono più indicate, invece, nella terapia empirica della classica polmonite acquisita in comunità, sostenuta prevalentemente, ancora oggi, dal pneumococco.

Nelle infezioni delle vie respiratorie acquisite in comunità sono oggi indicati $i$ fluorochinoloni appartenenti al gruppo $\mathrm{III}^{\circ} \mathrm{o}$ $\mathrm{IV}^{\circ}$. Nel gruppo $\mathrm{III}^{\circ}$ sono incluse la levofloxacina e la sparfloxacina, dotate di un ampio spettro antibatterico con aumentata potenza verso i Gram-positivi ed i patogeni atipici: queste molecole sono oggi indicate in modo specifico per il trattamento delle polmoniti acquisite in comunità e per le polmoniti atipiche. La sparfloxacina, tuttavia, presenta un alto grado di fototossicità.

Recentemente sono state sviluppate nuove molecole (moxifloxacina, gatifloxacina e gemifloxacina) ancora più attive verso alcuni Gram-positivi, pneumococco in particolare, e verso i patogeni atipici, e dotate anche di una buona attività nei confronti degli anaerobi, batteri notoriamente poco sensibili agli altri fluorochinoloni. Per tali caratteristiche microbiologiche questi nuovi fluorochinoloni sono stati classificati in un gruppo a parte, il gruppo $\mathrm{IV}^{\circ}$.

Attualmente, solo la moxifloxacina è entrata nell'uso clinico; inoltre, in Italia, la moxifloxacina è oggi disponibile solo nella forma
Tabella 1

Classificazione deifluorochinoloni (PEG 1998) [6]

\begin{tabular}{|c|c|c|}
\hline & Criteri & Antibiotici \\
\hline Gruppo $\mathrm{I}^{\circ}$ & $\begin{array}{l}\text { Fluorochinoloni con limitate indicazioni } \\
\text { (es. I.V.U.) }\end{array}$ & $\begin{array}{l}\text { Norfloxacina } \\
\text { Pefloxacina }\end{array}$ \\
\hline Gruppo II $^{\circ}$ & $\begin{array}{l}\text { Fluorochinoloni "classici" con ampio } \\
\text { spettro d'indicazioni, ma insufficiente } \\
\text { attività anti-pneumococcica }\end{array}$ & $\begin{array}{l}\text { Ciprofloxacina } \\
\text { Enoxacina } \\
\text { Fleroxacina (n.i.c.) } \\
\text { Ofloxacina }\end{array}$ \\
\hline Gruppo III $^{\circ}$ & $\begin{array}{l}\text { Fluorochinoloni con elevata attività } \\
\text { verso Gram-positivi e patogeni atipici }\end{array}$ & $\begin{array}{l}\text { Levofloxacina } \\
\text { Sparfloxacina (n.i.c.) }\end{array}$ \\
\hline Gruppo IV & $\begin{array}{l}\text { Fluorochinoloni con attività molto } \\
\text { elevata verso Gram-positivi, patogeni } \\
\text { atipici ed anaerobi }\end{array}$ & $\begin{array}{l}\text { Moxifloxacina } \\
\text { Gatifloxacina } \\
\text { Gemifloxacina }\end{array}$ \\
\hline
\end{tabular}

n.i.c. $=$ Non disponibile in commercio in Italia 
orale, mentre in USA, Germania e altri paesi europei è disponibile anche nella forma parenterale.

\section{PROFILOMICROBIOLOGICO}

La microbiologia clinica della moxifloxacina è stata documentata da numerose ricerche pubblicate negli ultimi anni e riassunte in diverse rassegne esaustive [7-10]. Gli studi microbiologici sono stati condotti su raccolte di ceppi d'isolamento clinico comprendenti batteri Gram-positivi, Gram-negativi, anaerobi, patogeni atipici [11-47]. La maggior parte delle ricerche microbiologiche ha focalizzato l'attenzione sui patogeni respiratori, nei confronti dei quali la moxifloxacina ha dimostrato di avere un'elevata attività battericida [31-38].

Infine, diverse ricerche hanno evidenziato l'attività antibatterica della moxifloxacina verso ceppi resistenti a penicillina, eritromicina, ciprofloxacina e vancomicina [39-47].

Un profilo comparativo dell'attività antibatterica in vitro della moxifloxacina verso i batteri Gram-negativi, Gram-positivi e verso i patogeni atipici è stato tracciato in una recente rassegna di Blondeau, che ha confrontato i dati microbiologici disponibili in letteratura per i principali fluorochinoloni e per alcuni altri antibiotici frequentemente utilizzati per via orale nelle infezioni delle vie respiratorie [8].

Le Tabelle 2-4 riassumono le attività in vitro $\left(\mathrm{MIC}_{90}\right)$ di tre fluorochinoloni (ciprofloxacina, levofloxacina e moxifloxacina), due macrolidi (claritromicina e azitromicina), due betalattamine (amoxicillina/clavulanato e cefuroxim) e un sulfamidico (cotrimossazolo), nei confronti rispettivamente dei batteri Gramnegativi, Gram-positivi e dei patogeni atipici.

La Tabella 2 indica che la ciprofloxacina, tra i fluorochinoloni considerati, è l'antibiotico più attivo verso le Enterobatteriaceae. I macrolidi e gli altri antibiotici considerati hanno invece MIC troppo elevate e non sono considerati attivi nei confronti delle Enterobatteriaceae.

Ciprofloxacina, levofloxacina e moxifloxacina sono molto attivi nei confronti di $H$. influenzae, M. catarrhalis e Neisseria spp.,

\section{Tabella 2}

Confronto dell'attività in vitro di 8 antibiotici nei confronti di batteri Gram-negativi (modificata da: Blondeau JM, 1999) [8]

\begin{tabular}{|c|c|c|c|c|c|c|c|c|}
\hline & \multicolumn{8}{|c|}{$\mathrm{MIC}_{90}(\mathrm{mg} / \mathrm{L})$} \\
\hline & Cotrimox & Co-Amox & Cefur & Clar & Azit & Cipro & Levo & Moxi \\
\hline Escherichia coli & $>16$ & $4-16$ & $4-16$ & ND & $4-16$ & $0,125-0,5$ & $0,06-<0,5$ & $0,06-1$ \\
\hline Enterobacter spp. & 2 & 8 & $>16$ & ND & 32 & 0,03 & $0,06-<0,5$ & 0,06 \\
\hline \multicolumn{9}{|l|}{ H. influenzae } \\
\hline$\beta$-lactamase + & $<0,05$ & $1-2$ & $2-4$ & -16 & $1-2$ & $0,015-0,03$ & $0,03-0,47$ & $0,03-0,06$ \\
\hline$\beta$-lactamase - & $<0,05$ & $1-2$ & $2-8$ & $8-24$ & $1-2$ & $0,015-0,03$ & $0,03-0,32$ & $0,03-0,06$ \\
\hline Kleb. pneumoniae & $>4$ & 8 & $8-16$ & ND & 64 & 0,25 & $0,12-0,25$ & $0,12-0,25$ \\
\hline Klebsiella spp. & $8->64$ & 8 & $4-64$ & ND & 64 & $0,03-0,25$ & $<0,015-0,25$ & 0,5 \\
\hline \multicolumn{9}{|l|}{ Moraxella catarrhalis } \\
\hline$\beta$-lactamase + & $0,25-0,5$ & 0,38 & 3 & $<0,06-0,38$ & $<0,06$ & $0,015-0,06$ & $0,06-0,094$ & $0,012-0,06$ \\
\hline$\beta$-lactamase - & $0,25-0,5$ & 0,38 & 2 & $0,06-4$ & $<0,06$ & $0,015-0,06$ & 0,06 & $0,012-0,06$ \\
\hline Morganella morganii & $>16$ & $32-512$ & $64-128$ & ND & $>128$ & 2 & 2 & 0,25 \\
\hline Neisseria spp. & ND & $0,12-1$ & $<0,06-0,25$ & $0,5-1$ & $0,12-0,5$ & 0,04 & 0,008 & 0,015 \\
\hline Proteus spp. & 16 & $<0,5-8$ & $1->32$ & ND & $>64$ & $<0,015-0,03$ & $0,03-<0,5$ & 0,025 \\
\hline Pseud. aeruginosa & $>16$ & $>128$ & $>128$ & ND & ND & $0,25-4$ & $0,5->4$ & 8 \\
\hline Stenotrophomonas & & & & & & & & \\
\hline maltophilia & ND & $>128$ & ND & ND & ND & 8 & 4 & $1-2$ \\
\hline Serratia spp. & 8 & $32-256$ & $128->256$ & ND & 64 & 1 & 2 & 4 \\
\hline Citrobacter spp. & $>16$ & 16 & $2->32$ & ND & ND & $<0,015$ & $<0,015$ & 0,12 \\
\hline
\end{tabular}

Cotrimox: cotrimossazolo; Co-Amox: amoxicillina/clavulanato; Cefur: cefuroxim; Clar: claritromicina; Azit: azitromicina;

Cipro: ciprofloxacina; Levo: levofloxacina; Moxi: moxifloxacina. 
batteri problematici perché responsabili di frequenti infezioni difficili da trattare con le betalattamine per le frequenti resistenze, mediate soprattutto dalla forte produzione di blattamasi. L'attività antibatterica dei fluorochinoloni non viene intaccata dalla produzione di b-lattamasi.

I dati riportati nella Tabella 3 evidenziano che la ciprofloxacina è meno attiva della levofloxacina e della moxifloxacina verso i batteri Gram-positivi.

I ceppi di S. aureus meticillino-sensibili (MSSA) sono molto sensibili a tutti i fluorochinoloni. La moxifloxacina, tuttavia, è otto volte più attiva della levofloxacina $\mathrm{e}$ fino $\mathrm{a}$ 64 volte più attiva della ciprofloxacina nei confronti dei ceppi di S. aureus meticillino-resistenti (MRSA).

L'attività della moxifloxacina verso i ceppi di $S$. pneumoniae è significativamente superiore a quella della levofloxacina e della ciprofloxacina. Complessivamente le MIC dei fluorochinoloni, a differenza degli altri antibiotici considerati in Tabella 3, non sono condizionate dalla ridotta sensibilità alla penicillina presente in molti ceppi d'isolamento di $S$. pneumoniae.

La moxifloxacina ha una buona attività anche verso alcune specie di enterococchi $(E$. fecalis e E. faecium) che rappresentano, oggi, uno dei principali problemi terapeutici a causa della crescente frequenza di ceppi vancomicina-resistenti rilevata in alcuni paesi (non ancora in Italia). L'attività della moxifloxacina verso gli enterocchi, nettamente superiore a quella della ciprofloxacina e di altri fluorochinoloni, non sembra tuttavia essere tale da poter contribuire in modo significativo a risolvere questo problema.

La Tabella 4 evidenzia l'elevata attività nei confronti dei patogeni atipici dimostrata mediamente dai fluorochinoloni e dai macrolidi e l'assenza di tale attività negli altri antibiotici considerati, betalattamine e cotrimossazolo. Ciprofloxacina, levofloxacina e moxifloxacina sono molto attive verso i ceppi di Legionella pneumophila. Moxifloxacina, azitromicina e claritromicina sono gli antibiotici più attivi verso i ceppi di Chlamydia spp. e di $M$. pneumoniae. Su questi due patogeni atipici la moxifloxacina è sensibilmente più attiva della levofloxacina e, in ordine successivo, della ciprofloxacina.

Ulteriori conferme dell'elevata attività della moxifloxacina verso i patogeni atipici sono state ottenute con ricerche più recenti [18-23].

L'elevata attività della moxifloxacina nei confronti dei patogeni anaerobi è stata documentata da diversi studi microbiologici, utilizzando raccolte di ceppi di isolamento clinico [24-30].

In un recente studio condotto in Germania l'attività in vitro della moxifloxacina è stata testata, in confronto con numerosi altri antibiotici, misurando la MIC su 292 ceppi di batteri anaerobi obbligati, isolati da casi clinici in Europa e negli Stati Uniti [27].

Il campione di microrganismi anaerobi era costituito in prevalenza da Bacteroides spp. (complessivamente 197 ceppi di 6 specie diffe-

Tabella 3

Confronto dell'attività in vitro di 8 antibiotici nei confronti di batteri Gram-positivi (modificata da: Blondeau JM, 1999) [8]

\begin{tabular}{|c|c|c|c|c|c|c|c|c|}
\hline & \multicolumn{8}{|c|}{$\mathrm{MIC}_{90}(\mathrm{mg} / \mathrm{L})$} \\
\hline & Cotrimox & Co-Amox & Cefur & Clar & Azit & Cipro & Levo & Moxi \\
\hline \multicolumn{9}{|l|}{ Enterococcus } \\
\hline faecalis & 2 & 0,5 & $0,03-256$ & $>64$ & $8->64$ & $2-64$ & $0,5-2$ & $0,5-8$ \\
\hline $\begin{array}{l}\text { Enterococcus } \\
\text { faecium }\end{array}$ & ND & 16 & ND & ND & ND & $4->128$ & $2-32$ & 2 \\
\hline \multicolumn{9}{|l|}{ Staph. Aureus } \\
\hline MSSA & $1-2$ & $0,05-1$ & $1-4$ & $0,25->8$ & $1->8$ & $0,5-1$ & 0,25 & 0,12 \\
\hline MRSA & $3,37->64$ & $>128$ & $>128$ & $>64$ & $>128$ & $32-128$ & 16 & 2 \\
\hline Staph. Epidermidis & 4 & 2 & $0,5-2$ & $8->64$ & $32->128$ & 8 & $0,5-1$ & 2 \\
\hline \multicolumn{9}{|l|}{ Strept. pneumoniae } \\
\hline Pen S & 1 & 0,03 & $0,06-0,25$ & $0,03-0,25$ & $0,06-0,12$ & $1-2$ & $1-2$ & $0,06-0,25$ \\
\hline Pen I & $8-16$ & 1 & $2-4$ & $4-64$ & $4-8$ & $1-2$ & $1-2$ & $0,12-0,25$ \\
\hline Pen R & $8-16$ & 4 & $8-16$ & $32->256$ & $>64$ & $1-2$ & $1-2$ & $0,12-0,25$ \\
\hline Strept. pyogenes & $1-4$ & 0,015 & $<0,12$ & 0,03 & $0,12-0,25$ & $1-2$ & 1 & 0,25 \\
\hline
\end{tabular}

Cotrimox: cotrimossazolo; Co-Amox: amoxicillina/clavulanato; Cefur: cefuroxim; Clar: claritromicina; Azit: azitromicina;

Cipro: ciprofloxacina; Levo: levofloxacina; Moxi: moxifloxacina. 
renti), con una buona rappresentanza di Clostridium spp. (29 ceppi), Fusobacterium spp. (17), Bilaphiola wadsworthia (29 ceppi), Prevotella spp. (11 ceppi) e Peptostreptococcus spp. (9 ceppi).

La Figura 1 riporta le distribuzioni cumulative percentuali delle MIC della moxifloxacina e di altri undici antibiotici misurate sui 292 ceppi di batteri anaerobi obbligati. La moxifloxacina è risultata essere il fluorochinolone più attivo nei confronti dei batteri anaerobi e uno dei più attivi tra gli antibiotici attualmente in uso, superato solo dai carbapenemi, meropenem e imipenem, e dal metronidazolo.

Considerando complessivamente tutti i ceppi testati, le $\mathrm{MIC}_{50 / 90}$ della moxifloxacina sono state stimate in $0,5 / 2 \mathrm{mg} / \mathrm{L}$, mentre quelle della levofloxacina e della ciprofloxacina erano rispettivamente di $2 / 16$ e $4 / 32 \mathrm{mg} / \mathrm{L}$.

I risultati di questo studio sono in accordo con quelli ottenuti in diverse altre rassegne microbiologiche precendenti e sono stati confermati anche da ricerche condotte in Italia [30].

$\mathrm{Si}$ deve, dunque, ritenere che la moxifloxacina, a differenza della ciprofloxacina e della levofloxacina, possa essere utile nel trattamento delle infezioni sostenute da batteri anaerobi.

Numerose ricerche di microbiologia clinica, condotte in diversi paesi negli ultimi anni, hanno ulteriormente documentato, confermando i dati precedenti, che la moxifloxacina mantiene elevata attività battericida anche nei confronti della maggior parte dei ceppi di patogeni d'isolamento clinico risultati resistenti alla penicillina, all'eritromicina, alla vancomicina e alla stessa ciprofloxacina [39-47].

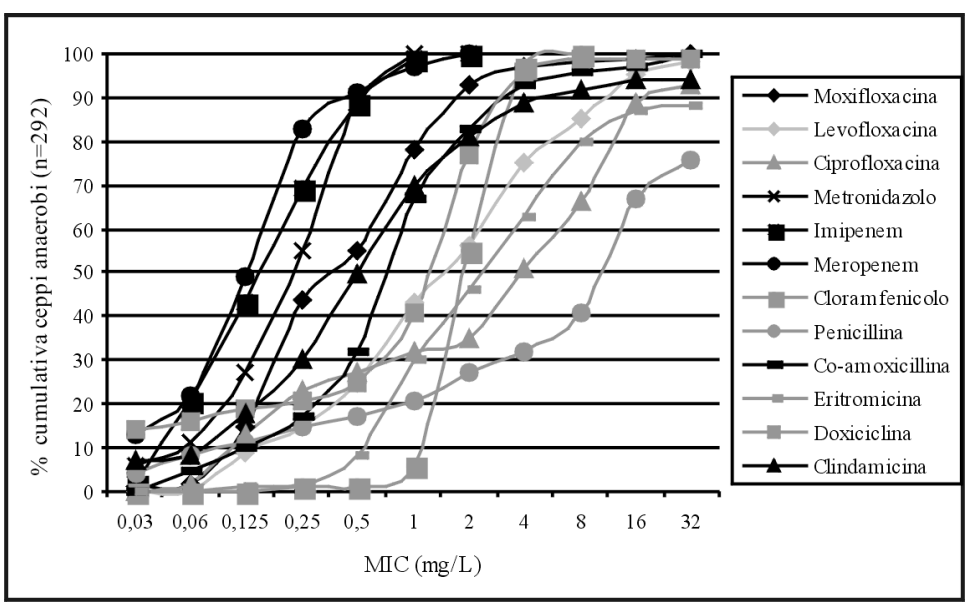

Figura 1

Distribuzione cumulativa percentuale di 292 ceppi di anaerobi obbligatori rispetto alle MIC di moxifloxacina e di altri antibiotici (da Schaumann et al, 2000) [27]

\section{MECCANISMOD'AZIONE E RESISTENZA ACQUISITA}

I fluorochinoloni esplicano la loro attività battericida inibendo direttamente la sintesi del DNA. Questo risultato è conseguenza dell'interazione del fluorochinolone con due diversi target enzimatici situati all'interno della cellula batterica: la DNA girasi (topoisomerasi II) e la topoisomerasi IV [48].

La DNA girasi è un eterotetramero, costituito da due subunità $\mathrm{A}$ (GyrA), codificate dal gene gyrA, e da due subunità B (GyrB), codificate dal gene gyrB. La DNA girasi induce la "superelicazione negativa" del DNA batterico, tappa essenziale per la replicazione e la trascrizione del codice genetico. La topoisomerasi IV è un eterotetramero costituito da due subunità

\section{Tabella 4}

Confronto dell'attività in vitro di 8 antibiotici nei confronti di patogeni atipici (modificata da: Blondeau JM, 1999) [8]

\begin{tabular}{|c|c|c|c|c|c|c|c|c|}
\hline & \multicolumn{8}{|c|}{$\mathrm{MIC}_{90}(\mathrm{mg} / \mathrm{L})$} \\
\hline & Cotrimox & Co-Amox & Cefur & Clar & Azit & Cipro & Levo & Moxi \\
\hline $\begin{array}{l}\text { Chlamydia } \\
\text { pneumoniae }\end{array}$ & ND & ND & ND & 0,03 & 0,25 & $1-2$ & $0,25-0,5$ & $0,03-1$ \\
\hline $\begin{array}{l}\text { Chlamydia } \\
\text { trachomatis }\end{array}$ & ND & ND & ND & ND & 0,12 & 2 & $0,25-0,5$ & $0,03-0,125$ \\
\hline $\begin{array}{l}\text { Legionella } \\
\text { pneumophila }\end{array}$ & ND & ND & ND & $0,03-0,06$ & 0,25 & 0,12 & 0,03 & 0,015 \\
\hline $\begin{array}{l}\text { Mycoplasma } \\
\text { pneumoniae }\end{array}$ & ND & ND & ND & $0,008-0,03$ & 0,002 & $0,78-8$ & ND & $0,06-0,12$ \\
\hline
\end{tabular}

Cotrimox: cotrimossazolo; Co-Amox: amoxicillina/clavulanato; Cefur: cefuroxim; Clar: claritromicina; Azit: azitromicina;

Cipro: ciprofloxacina; Levo: levofloxacina; Moxi: moxifloxacina. 
C (ParC), codificate dal gene parC, e da due subunità $\mathrm{E}$ (ParE), codificate dal gene parE. La topoisomerasi IV ha la funzione di separare le due catene di DNA figlie, dopo la replicazione, consentendo la segregazione dei cromosomi replicati.

Il fluorochinolone, legandosi alla DNA girasi e alla topoisomerasi IV impedisce la normale progressione della replicazione del DNA e quindi provoca la morte della cellula batterica.

Recenti lavori hanno dimostrato che $\mathrm{i}$ fluorochinoloni noti si differenziano per il loro target preferenziale: alcuni inibiscono maggiormente la topoisomerasi IV (norfloxacina, enoxacina, fleroxacina, ciprofloxacina, lomefloxacina, trovafloxacina, grepafloxacina, ofloxacina e levofloxacina), altri la DNA girasi (sparfloxacina, nadifloxacina), mentre moxifloxacina, gatifloxacina e clinafloxacina inibiscono in modo bilanciato i due target enzimatici [49-51].

La resistenza ai fluorochinoloni è mediata principalmente da tre meccanismi: 1) mutazioni dei geni che codificano la sintesi degli enzimi target; 2) mutazioni dei geni che regolano l'espressione delle porine e la permeabilità batterica all'antibiotico; 3) mutazioni dei geni che regolano l'espressione delle pompe efflusso che hanno la funzione di trasportare l'antibiotico all'esterno del microrganismo [52-58].

Le mutazioni del gene gyrA sono tra le cause più frequenti di resistenza ai chinoloni riscontrate tra i batteri Gram-negativi, mentre le mutazioni del gene parC sono tra le cause di resistenza più comunemente riscontrate tra $\mathrm{i}$ batteri Gram-positivi. Meno frequentemente sono state osservate mutazioni anche dei geni gyrB e parE [54].

Le mutazioni responsabili delle resistenze ai chinoloni avvengono prevalentemente in una regione ristretta dei geni gyrA e parC coinvolgendo nella maggior parte dei casi gli aminoacidi 83 e 87 delle due subunità enzimatiche GyrA e ParC, rispettivamente della DNA girasi e della topoisomerasi IV.

Altre forme di resistenza a bassa concentrazione ai chinoloni sono state osservate in batteri Gram-negativi che presentavano una ridotta permeabilità delle porine. Recentemente sono state osservate forme più importanti di resistenze ai chinoloni dovute all'aumentata espressione delle pompe efflusso sia in batteri Gram-negativi che Gram-positivi. In particolare, questa forma di resistenza è stata attribuita all'aumentata espressione della pompa NorA negli stafilococchi e della pompa PmrA nei pneumococchi [52,53].

L'insorgenza di resistenza è un processo a gradini successivi, ognuno dei quali correlato ad una diversa mutazione: ad ogni gradino la sensibilità del microrganismo al chinolone diminuisce di 4-8 volte. Il percorso lungo il quale si sviluppa questo processo a gradini differisce in relazione sia al tipo di patogeno sia al tipo di fluorochinolone che induce resistenza [57].

Antibiotici come la moxifloxacina che inibiscono contemporaneamente e in ugual misura la DNA girasi e la topoisomerasi IV dimostrano minor tendenza ad indurre e selezionare ceppi resistenti, rispetto ad analoghi strutturali che inibiscono prevalentemente l'uno o l'altro target enzimatico [55-56].

L'effetto inibitorio bilanciato della moxifloxacina sulla DNA girasi e sulla topoisomerasi IV è stato posto in relazione con la sua minore perdita di attività nei confronti di ceppi mutanti gyrA e parC, rispetto ad altri fluorochinoloni che inibiscono preferenzialmente o la DNA girasi o la topoisomerasi IV.

In particolare, la MIC della moxifloxacina nei confronti di ceppi di $S$. pneumoniae con doppie mutazioni geniche gyrA e parC non è mai superiore a $2 \mathrm{mg} / \mathrm{L}$, un valore compatibile con le concentrazioni raggiungibili in vivo utilizzando dosi terapeutiche del farmaco [55].

L'elevata attività della moxifloxacina verso $S$. pneumoniae è garantita anche dal ridotto efflusso dell' antibiotico dalle cellule batteriche [53].

Si ritiene che la probabilità di avere contemporaneamente due o più mutazioni in un patogeno sia molto bassa. In pratica, quindi, per evitare il rischio di selezionare un ceppo resistente è sufficiente indurre nel sito d'infezione concentrazioni di antibiotico capaci di inibire la crescita di cellule batteriche che abbiano una singola mutazione: la più bassa concentrazione capace di inibire la crescita di ceppi resistenti a singola mutazione è stata definita come Mutant Prevention Concentration (MPC), ossia come concentrazione limite al di sopra della quale la proliferazione selettiva di mutanti resistenti dovrebbe essere inibita o poco probabile [58].

La moxifloxacina, tra i fluorochinoloni più recenti, ha dimostrato di possedere una MPC significativamente inferiore e quindi una potenza maggiore nel ridurre il rischio di selezionare ceppi resistenti.

Ancora più significativo è il fatto che i valori di $\mathrm{MPC}_{90}$ della moxifloxacina sono generalmente inferiori alle concentrazioni di picco ottenibili in vivo con dosi terapeutiche di antibiotico [58].

\section{FARMACODINAMICA}

La moxifloxacina, come ogni altro fluorochinolone, agisce con una dinamica battericida concentrazione-dipendente [59-62]. Inoltre, manifesta un significativo effetto post- 
antibiotico (PAE) sia nei batteri Gram-positivi sia nei batteri Gram-negativi. L'effetto postantibiotico varia come durata nei vari patogeni da circa 1,5 a 2,5 ore $[62,63]$.

Una serie di studi, condotti in vitro con modelli di simulazione e in vivo con modelli di infezione animale e con trial clinici, ha dimostrato che, nel caso di antibiotici a dinamica concentrazione-dipendente, due sono i parametri che meglio correlano l'esposizione all'antibiotico con l'eradicazione batteriologica e con la prevenzione dello sviluppo di resistenze:

1. il rapporto tra l'Area sotto la Curva delle Concentrazioni (AUC) dell' antibiotico nelle 24 ore e la concentrazione minima inibente (MIC) del patogeno responsabile dell'infezione. Questo rapporto viene anche definito come AUIC (Area Under Inhibitory Curve);

2. il rapporto tra concentrazione di picco massimo (Cmax) e MIC, ossia Cmax/MIC.

Indipendentemente dalla classe di antibiotico, un valore di AUIC superiore a 125 e un valore di Cmax/MIC superiore a 10 sono ritenuti ottimali per rendere massima la probabilità di eradicazione del patogeno e rendere minima la probabilità di selezionare ceppi resistenti. D'altra parte, valori di AUIC $<100$ e di Cmax/ MIC $<3$ sono stati correlati con l'insorgenza di resistenze [64].

Gli studi effettuati con modelli in vitro hanno dimostrato che la moxifloxacina è dotata di un elevato potere battericida nei confronti dei ceppi sensibili [65-74].

Grazie alle sue caratteristiche farmaco-cinetiche (vedi oltre) e ai valori di MIC molto bassi per la maggior parte dei patogeni sensibili, la moxifloxacina presenta valori di AUIC nettamente superiori a 125 e di Cmax/MIC nettamente superiori a 10 per la maggior parte dei patogeni responsabili delle infezioni delle vie respiratorie.

Nella Tabella 5 riportiamo i valori delle AUIC e delle $\mathrm{Cmax} / \mathrm{MIC}$ della moxifloxacina, in confronto con quelli della ciprofloxacina e della levofloxacina, riferiti alle MIC90 dello $S$. pneumoniae, $H$. influenzae e $M$. catarrhalis, i tre principali patogeni responsabili delle infezioni delle vie respiratorie. Moxifloxacina induce valori di AUIC e di Cmax/MIC nettamente superiori a quelli ottimali e superiori anche a quelli indotti da ciprofloxacina e da levofloxacina. Tutti tre i fluorochinoloni considerati presentano AUIC $>125$ e Cmax/MIC > 10 nei confronti di $H$. influenzae e di $M$. catarrhalis, ma solo moxifloxacina dimostra un' adeguata attività battericida nei confronti del $90 \%$ dei ceppi di S. pneumoniae.

\section{FARMACOCINETICA}

La farmacocinetica clinica della moxifloxacina è stata studiata in gruppi di volontari sani e di pazienti dopo somministrazione di dose singola o ripetuta per via orale e per via endovenosa [75-97].

I principali parametri farmacocinetici della moxifloxacina dopo somministrazione orale sono riassunti e confrontati con quelli della ciprofloxacina e della levofloxacina nelle Tabelle 6 e $7[59,81]$.

La farmacocinetica della moxifloxacina è lineare nel range di dosi orali testate comprese

\begin{tabular}{|c|c|c|c|}
\hline & Ciprofloxacina & Levofloxacina & Moxifloxacina \\
\hline Dose & $500 \mathrm{mg}$ bid & $500 \mathrm{mg}$ od & $400 \mathrm{mg}$ od \\
\hline $\mathrm{C}_{\max }(\mathrm{mg} / \mathrm{L})$ & 2,30 & 5,08 & 3,34 \\
\hline $\mathrm{AUC}_{24}(\mathrm{mg} / \mathrm{L} \times \mathrm{h})$ & 10,1 & 48,0 & 33,8 \\
\hline \multicolumn{4}{|l|}{ Streptococcus pneumoniae } \\
\hline $\mathrm{MIC}_{90}(\mathrm{mg} / \mathrm{L})$ & 2 & 2 & 0,25 \\
\hline $\mathrm{AUC}_{24} / \mathrm{MIC}_{90}(\mathrm{AUIC})$ & 5 & 24 & 135 \\
\hline $\mathrm{C}_{\max } / \mathrm{MIC}_{90}$ & 1,15 & 2,54 & 13,36 \\
\hline \multicolumn{4}{|l|}{ Haemophilus influenzae } \\
\hline $\mathrm{MIC}_{90}(\mathrm{mg} / \mathrm{L})$ & 0,03 & 0,47 & 0,06 \\
\hline $\mathrm{AUC}_{24} / \mathrm{MIC}_{90}(\mathrm{AUIC})$ & 337 & 102 & 563 \\
\hline $\mathrm{C}_{\max } / \mathrm{MIC}_{90}$ & 200 & 11 & 56 \\
\hline \multicolumn{4}{|l|}{ Moraxella catarrhalis } \\
\hline $\mathrm{MIC}_{90}(\mathrm{mg} / \mathrm{L})$ & 0,06 & 0,094 & 0,06 \\
\hline $\mathrm{AUC}_{24} / \mathrm{MIC}_{90}(\mathrm{AUIC})$ & 168 & 510 & 563 \\
\hline $\mathrm{C}_{\max } / \mathrm{MIC}_{90}$ & 38 & 54 & 56 \\
\hline
\end{tabular}

Tabella 5

Parametri farmacodinamici di ciprofloxacina, levofloxacina e moxifloxacina nei confronti dei tre principali patogeni polmonari. Valori di MIC $C_{90}$ assunti dalle Tabelle 2 e 3 .

Parametri

farmacocinetici stimati dopo dose singola orale, come riferiti da Zhanel et al, 2001 [59] 
Tabella 6

Parametri

farmacocinetici stimati

in un gruppo di

volontari sani dopo

singola dose orale

di ciprofloxacina,

levofloxacina o

moxifloxacina

(modificata da:

Lubasch et al, 2000)

[81]

\section{Tabella 7}

Parametri

farmacocinetici clinici

dopo singola dose

orale di ciprofloxacina,

levofloxacina o

moxifloxacina

(modificata da: Zhanel

et al, 2002) [59]

\begin{tabular}{lccc}
\hline & $\begin{array}{c}\text { Ciprofloxacina } \\
\mathbf{2 5 0} \mathbf{m g}\end{array}$ & $\begin{array}{c}\text { Levofloxacina } \\
\mathbf{5 0 0} \mathbf{m g}\end{array}$ & $\begin{array}{c}\text { Moxifloxacina } \\
\mathbf{4 0 0} \mathbf{m g}\end{array}$ \\
\hline $\mathrm{C}_{\text {max }}(\mu \mathrm{g} / \mathrm{ml} / 70 \mathrm{~kg})$ & $1,50 \pm 0,43$ & $6,21 \pm 1,34$ & $4,34 \pm 1,61$ \\
$\mathrm{~T}_{\text {max }}(\mathrm{h})$ & $0,78 \pm 0,33$ & $0,80 \pm 0,38$ & $1,02 \pm 0,72$ \\
Emivita $(\mathrm{h})$ & $5,37 \pm 0,82$ & $6,95 \pm 0,81$ & $9,15 \pm 1,62$ \\
Mean Residence Time $(\mathrm{h})$ & $5,80 \pm 0,94$ & $8,65 \pm 0,80$ & $12,5 \pm 2,03$ \\
$\mathrm{AUC}(\mathrm{h} x \mu \mathrm{g} / \mathrm{ml} / 70 \mathrm{~kg})$ & $5,75 \pm 1,25$ & $44,8 \pm 4,40$ & $39,3 \pm 5,35$ \\
Escrezione urinaria & & & \\
$\quad(\%$ immodificata) & $40,8 \pm 7,48$ & $75,9 \pm 11,6$ & $19,9 \pm 4,55$ \\
Clearance renale $\left(\mathrm{ml} / \mathrm{min} / 1,73 \mathrm{~m}^{2}\right)$ & $266 \pm 40,6$ & $124 \pm 19,1$ & $30,5 \pm 6,18$ \\
Volume Vss $(\mathrm{L} / 70 \mathrm{Kg})$ & $231 \pm 61,8$ & $88 \pm 9,9$ & $122 \pm 19,6$ \\
\hline
\end{tabular}

tra 50mg e 800mg: le concentrazioni di picco massimo (Cmax) e l'AUC aumentano in modo proporzionale alle dosi, mentre l'emivita e la clearance sistemica non si modificano significativamente [75].

Somministrata per via orale, la moxifloxacina viene quasi completamente assorbita inducendo concentrazioni di picco entro 1-2 ore dalla somministrazione: la biodisponibilità assoluta orale è stata stimata tra l' $86 \%$ e il $92 \%$ [76,77].

La presenza di cibo non modifica la biodisponibilità della moxifloxacina [78]. La concomitante assunzione di yogurt o altri prodotti caseari non altera significativamente la biodisponibilità orale della moxifloxacina [79]. La contemporanea assunzione di integratori o farmaci a base di calcio rallenta l' assorbimento di moxifloxacina senza, tuttavia, ridurre significativamente i valori di Cmax e di AUC [80]. Pertanto la moxifloxacina può essere somministrata con gli alimenti e con integratori di calcio.

La moxifloxacina, nel volontario sano, presenta un'emivita di eliminazione di 10-14 ore, nettamente più lunga di quella della ciprofloxacina e della levofloxacina [59, 81].

Dopo somministrazioni a dosi ripetute con intervalli di 24 ore l'accumulo del farmaco è sensibile, ma non eccessivo, e risulta ben controllabile, essendo la farmacocinetica lineare nel range di dosi terapeutiche [82]. Utilizzando la dose standard di $400 \mathrm{mg} /$ die le Cmax allo steady-state sono di poco superiori alle Cmax misurate dopo la prima dose, mentre le concentrazioni di valle (Cmin) sono più elevate di circa il $50 \%$, passando da $0,40 \mathrm{mg} / \mathrm{L}$ a 0,60 $\mathrm{mg} / \mathrm{L}$. Questi dati confermano che una singola dose giornaliera di 400mg di moxifloxacina è sufficiente e adeguata per indurre concentrazioni plasmatiche di antibiotico superiori alle $\mathrm{MIC}_{90}$ dei comuni patogeni delle vie respiratorie per tutto l'intervallo fra le dosi [82].

La moxifloxacina viene escreta immodificata nelle urine in una quota inferiore al $20 \%$ della dose: il farmaco viene parzialmente riassorbito a livello tubulare. La clearance renale della moxifloxacina è nettamente inferiore a quella della ciprofloxacina e della levofloxacina $[75,81]$.

La moxifloxacina viene eliminata prevalentemente per via metabolica mediante due reazioni di coniugazione $\left(\right.$ Fase $\left.\mathrm{II}^{\circ}\right)$ : una solfatazione che produce M1 e una di glucuronazione dalla quale origina $\mathrm{M} 2$, entrambe molecole prive di attività antibiotica (metaboliti inattivi). M1 rappresenta circa il $40 \%$ della dose, è legato per oltre il $90 \%$ alle proteine plasmatiche e viene escreto in gran parte per via fecale; M2, invece, è scarsamente lega-

\begin{tabular}{lcccccc} 
& \multicolumn{2}{c}{ Ciprofloxacina } & Levofloxacina & \multicolumn{2}{c}{ Moxifloxacina } \\
\hline Dose & $500 \mathrm{mg}$ & $750 \mathrm{mg}$ & $500 \mathrm{mg}$ & $750 \mathrm{mg}$ & $200 \mathrm{mg}$ & $400 \mathrm{mg}$ \\
Biodisponibilità orale $\mathrm{F}$ & $70 \%$ & $70 \%$ & $99 \%$ & $99 \%$ & $86 \%$ & $86 \%$ \\
$\mathrm{C}_{\max }(\mu \mathrm{g} / \mathrm{ml})$ & 2,30 & 3,00 & 5,08 & 7,13 & 1,16 & 3,34 \\
$\mathrm{~T}_{\max }(\mathrm{h})$ & 1,2 & 1,2 & 1,7 & 1,7 & 1,7 & 1,7 \\
$\mathrm{AUC}(\mu \mathrm{g} / \mathrm{ml} \mathrm{x} \mathrm{h})$ & 10,1 & 14,0 & 48,0 & 82,0 & 15,4 & 33,8 \\
Emivita $(\mathrm{h})$ & 3,5 & 3,5 & 6,9 & 6,9 & 12,1 & 12,1 \\
$\begin{array}{l}\text { Volume/F }(\mathrm{L} / \mathrm{kg}) \\
\text { Legame con proteine }\end{array}$ & 3,5 & 3,5 & 1,1 & 1,1 & 3,3 & 3,3 \\
$\begin{array}{l}\text { Escrezione urinaria } \\
\quad \% \text { immodificata }\end{array}$ & $30 \%$ & $30 \%$ & $31 \%$ & $31 \%$ & $48 \%$ & $48 \%$ \\
$\begin{array}{l}\text { Aggiustamento dose } \\
\text { nel nefropatico }\end{array}$ & $34 \%$ & $34 \%$ & $83 \%$ & $83 \%$ & $19 \%$ & $19 \%$ \\
$\begin{array}{l}\text { Aggiustamento dose } \\
\quad \text { nell'epatopatico }\end{array}$ & $\mathrm{Si}$ & $\mathrm{Si}$ & $\mathrm{Si}$ & $\mathrm{Si}$ & $\mathrm{No}$ & No \\
\hline
\end{tabular}


to alle proteine $(5 \%)$, rappresenta circa il $14-$ $15 \%$ della dose e si ritrova solo nelle urine. Le concentrazioni plasmatiche dei due metaboliti sono molto inferiori a quelle della moxifloxacina.[77]

La farmacocinetica della moxifloxacina non è influenzata dal sesso e dall'età del soggetto [83]. L'insufficienza renale esplica solo un modesto effetto sulla farmacocinetica plasmatica della moxifloxacina e del suo metabolita M1, mentre modifica significativamente la farmacocinetica plasmatica del metabolita M2, prolungandone la permanenza nell'organismo [84]. Tali modificazioni, tuttavia, non sono ritenute rilevanti sotto il profilo clinico e, in caso di insufficienza renale, non è richiesto di modificare la posologia della moxifloxacina, mentre ciò è necessario quando venga usata la ciprofloxacina o la levofloxacina (Tabelle 6, 7) [59].

Il legame con le proteine plasmatiche è inferiore al $50 \%$ e non influenza la distribuzione tissutale e l'escrezione della moxifloxacina.

La moxifloxacina diffonde rapidamente nei liquidi extravascolari, dove le sue concentrazioni (quota libera) si pongono in equilibrio con quelle plasmatiche raggiungendo valori simili e AUC sostanzialmente sovrapponibili [85]. Le concentrazioni della quota libera di moxifloxacina sono in equilibrio in tutti i tessuti, nel plasma e nella saliva; la flogosi sembra, tuttavia, favorire la penetrazione dell' antibiotico, inducendo concentrazioni superiori a quelle plasmatiche [86].

Le concentrazioni di moxifloxacina sono state misurate dopo singola dose orale di $400 \mathrm{mg}$ nei liquidi e tessuti polmonari di soggetti sottoposti a broncoscopia e nella mucosa dei seni nasali di pazienti trattati con $400 \mathrm{mg} /$ die e sottoposti ad intervento chirurgico $[87,88]$.

Dopo singola dose orale $(400 \mathrm{mg})$ le concentrazioni di moxifloxacina nel secreto bronchiale, nel tessuto bronchiale e nei macrofagi alveolari raggiungono concentrazioni notevolmente più elevate di quelle sieriche anche dopo 24 ore dalla somministrazione (Figura 2).

Durante l'intervallo fra le dosi le concentrazioni nei liquidi e tessuti polmonari sono

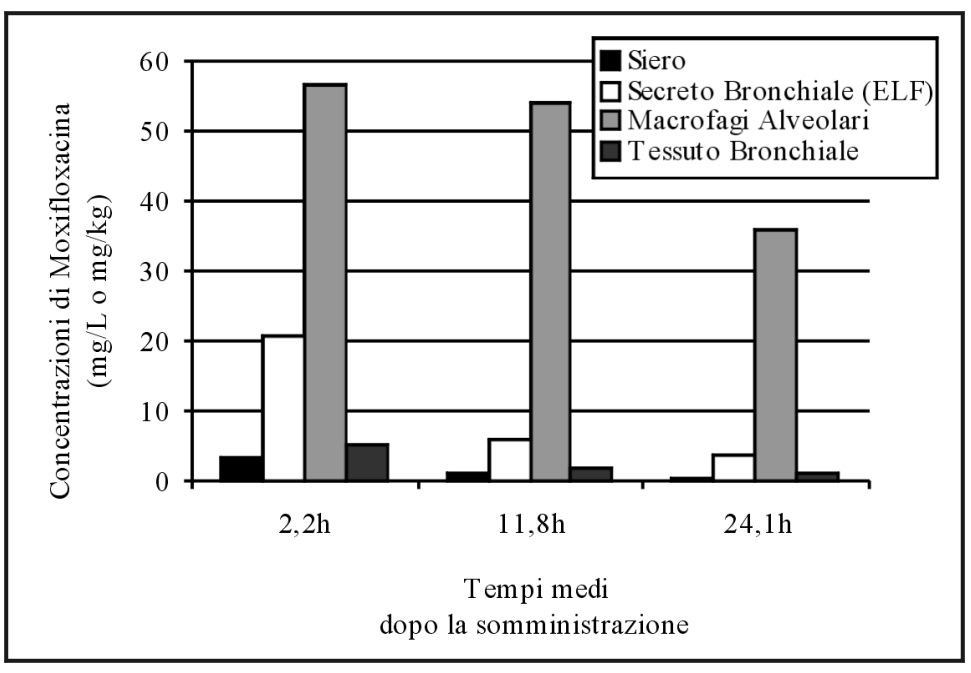

Figura 2

Concentrazioni (medie geometriche) di moxifloxacina misurate nel siero, nel secreto bronchiale (ELF), nei macrofagi alveolari e nel tessuto bronchiale (biopsie) di soggetti sottoposti a broncoscopia, trattati con dosi singole di moxifloxacina (400mg) [87]

molte volte superiori alle $\mathrm{MIC}_{90}$ dei comuni patogeni respiratori quali lo Streptococcus pneumoniae $(0,25 \mathrm{mg} / \mathrm{L})$, l'Haemophilus influenzae $(0,02 \mathrm{mg} / \mathrm{L})$, la Moraxella catarrhalis $(0,12 \mathrm{mg} / \mathrm{L})$, la Clamydia pneumoniae $(0,12 \mathrm{mg} / \mathrm{L})$ e il Mycoplasma pneumoniae $(0,12 \mathrm{mg} / \mathrm{L})$ [87] .

I valori delle AUIC di questi patogeni rispetto alle AUC misurate nei vari distretti polmonari risultano sempre notevolmente superiori a 125 , valore soglia ritenuto ottimale, nel caso di antibiotici ad azione concentrazione-dipendente, per garantire una completa e rapida batteriocidia e ridurre il rischio di insorgenza di resistenze (Tabella 8).

Concentrazioni due-tre volte superiori a quelle sieriche sono state misurate nella mucosa dei seni mascellari, etmoidali e nei polipi nasali in soggetti trattati con dosi multiple di moxifloxacina $400 \mathrm{mg} /$ die e sottoposti ad intervento chirurgico [88].

Anche in questo caso le concentrazioni tissutali permanevano per tutto l'intervallo fra le dosi a livelli superiori alla maggior parte dei patogeni responsabili delle infezioni delle mucose dei seni nasali.

\begin{tabular}{|c|c|c|c|c|}
\hline & \multirow{2}{*}{$\begin{array}{c}\text { AUC } \\
(\mathrm{mg} / \mathrm{L} \times \mathrm{x})\end{array}$} & \multicolumn{3}{|c|}{ AUIC (AUC/MIC) } \\
\hline & & $\begin{array}{c}\text { S. pneumoniae } \\
\left(\mathrm{MIC}_{90}=0,25 \mathrm{mg} / \mathrm{L}\right)\end{array}$ & $\begin{array}{c}\text { H. influenzae } \\
\left(\mathrm{MIC}_{90}=0,03 \mathrm{mg} / \mathrm{L}\right)\end{array}$ & $\begin{array}{c}\text { M. catarrhalis } \\
\left(\mathrm{MIC}_{90}=0,12 \mathrm{mg} / \mathrm{L}\right)\end{array}$ \\
\hline Siero & 36,5 & 145 & 1.210 & 302 \\
\hline Mucosa bronchiale & 53,8 & 215 & 1.793 & 448 \\
\hline Secreto bronchiale (ELF) & 189 & 756 & 6.300 & 1.575 \\
\hline Macrofagi alveolari & 496 & 1.984 & 16.533 & 4.133 \\
\hline
\end{tabular}

\section{Tabella 8}

Media delle AUC di moxifloxacina nel siero, nei liquidi e tessuti polmonari misurate dopo singola dose orale di $400 \mathrm{mg}$ e media delle AUIC relative alle $M I C_{90}$ dei tre principali patogeni polmonari [87] 
La moxifloxacina, oltre che nei macrofagi alveolari, si accumula anche nei neutrofili, raggiungendo concentrazioni molto elevate e circa 12 volte superiori a quelle esterne [89].

All'interno dei macrofagi e dei polimorfonucleati, la moxifloxacina mantiene un'elevata efficacia battericida, senza alterare la funzione fagocitaria. Inoltre, i neutrofili vengono attratti e si concentrano nella sede d'infezione, dove possono rilasciare l' antibiotico, contribuendo a potenziare l'azione battericida e a ridurre la carica batterica infettante [90].

\section{INTERAZIONIFARMACOLOGICHE}

Uno dei fattori che può favorire il successo di un antibiotico consiste nella mancanza o scarsità di interazioni farmacologiche clinicamente rilevanti, qualità che ne migliora il profilo di sicurezza e la maneggevolezza e contribuisce a ridurre i costi di terapia.

Le interazioni farmacologiche con la moxifloxacina sono state studiate mediante una serie di ricerche appositamente predisposte, selezionando i farmaci noti per le loro interferenze farmacocinetiche con altri fluorochinoloni, come la teofillina, oppure i farmaci con un ristretto range terapeutico, come la digossina, o quelli più frequentemente associati, come i contraccettivi orali [91-97]. Nella Tabella 9 è riassunto il profilo delle interazioni farmacologiche studiate [96].
L'assorbimento e la biodisponibilità orale di moxifloxacina non vengono influenzate da variazioni del $\mathrm{pH}$ prodotte da ranitidina [91], mentre l'assorbimento orale della moxifloxacina è ridotto quando vengano somministrati contemporaneamente antiacidi e preparati contenenti cationi polivalenti, quali ferro o alluminio, capaci di formare complessi insolubili con i chinoloni $[92,93]$. Per evitare questa interazione è sufficiente assumere la moxifloxacina 2 ore prima o 4 ore dopo la somministrazione dei preparati contenenti cationi di alluminio o di ferro.

A differenza di altri fluorochinoloni, la moxifloxacina non risente in modo marcato della presenza di ioni calcio [80].

Nessun'altra interazione clinicamente significativa è stata osservata tra moxifloxacina e farmaci associati. In particolare, la moxifloxacina non interagisce con la teofillina e si possono escludere interazioni metaboliche a livello del sistema citocromo P-450 [94]. Questo aspetto differenzia nettamente la moxifloxacina dagli altri fluorochinoloni che vengono metabolizzati da uno o più citocromi $\mathrm{P}-450$.

Infine, nessuna interazione clinicamente rilevante è stata documentata a livello renale tra probenecid e moxifloxacina [95].

Pertanto, sotto il profilo delle interazioni farmacologiche la moxifloxacina evidenzia una notevole maneggevolezza e sicurezza [97].

\section{Tabella 9}

Profilo delle interazioni farmacologiche con la moxifloxacina (modificata da Stass \& Kubitza, 2001) [96]

\begin{tabular}{|c|c|c|c|}
\hline Farmaco associato & $\begin{array}{l}\text { Tipo di } \\
\text { interazione }\end{array}$ & Razionale dello studio & $\begin{array}{l}\text { Presenza di } \\
\text { Interazione }\end{array}$ \\
\hline Ranitidina & Assorbimento & $\begin{array}{l}\text { Analizzare l'influenza del pH } \\
\text { sull'assorbimento di moxifloxacina }\end{array}$ & No \\
\hline $\begin{array}{l}\text { Preparati con } \mathrm{Al}^{3+} \\
\text { (Maalox) }\end{array}$ & Assorbimento & $\begin{array}{l}\text { Effetto di classe noto } \\
\text { per i fluorochinoloni }\end{array}$ & $\mathrm{Si}$ \\
\hline Sucralfato & Assorbimento & $\begin{array}{l}\text { Effetto di classe noto } \\
\text { per i fluorochinoloni }\end{array}$ & $\mathrm{Si}$ \\
\hline Preparati con ferro & Assorbimento & $\begin{array}{l}\text { Effetto di classe noto } \\
\text { per i fluorochinoloni }\end{array}$ & $\mathrm{Si}$ \\
\hline Integratori di $\mathrm{Ca}^{2+}$ & Assorbimento & $\begin{array}{l}\text { Effetto di classe noto } \\
\text { per i fluorochinoloni }\end{array}$ & No \\
\hline Digossina & $\begin{array}{l}\text { Distribuzione e/o } \\
\text { farmacodinamica }\end{array}$ & Range terapeutico ristretto & No \\
\hline Teofillina & Metabolismo & $\begin{array}{l}\text { Frequente associazione ed effetto } \\
\text { noto per alcuni fluorochinoloni }\end{array}$ & No \\
\hline Contraccettivi orali & $\begin{array}{l}\text { Farmacodinamica } \\
\text { e/o metabolismo }\end{array}$ & Riportato per alcuni antibiotici & No \\
\hline Warfarina & $\begin{array}{l}\text { Farmacodinamica } \\
\text { e/o metabolismo }\end{array}$ & Range terapeutico ristretto & No \\
\hline Gliburide & $\begin{array}{l}\text { Farmacodinamica } \\
\text { e/o metabolismo }\end{array}$ & Frequente associazione & No \\
\hline Probenecid & Escrezione & $\begin{array}{l}\text { Studiare il meccanismo } \\
\text { di eliminazione renale }\end{array}$ & No \\
\hline
\end{tabular}




\section{EFFICACIA CLINICAE BATTERIOLOGICANELLEINFEZIONI ACUTEDELLEVIE RESPIRATORIE}

Le caratteristiche microbiologiche, farmacocinetiche e farmacodinamiche della moxifloxacina risultano ottimali per un suo utilizzo nella terapia delle infezioni acute delle basse e alte vie respiratorie. In particolare, l'elevata attività battericida verso i principali patogeni respiratori, compreso i ceppi resistenti alla penicillina e all'eritromicina, la rapidità d'azione e la ridotta tendenza a selezionare ceppi resistenti, l'elevata biodisponibilità orale e la lunga emivita sono i fattori che maggiormente ne orientano l'impiego nelle polmoniti acquisite in comunità (CAP), nelle riacutizzazioni delle bronchiti croniche (AECB) e nelle sinusiti acute batteriche (ABS) [2, 5-7, 98-100].

L'efficacia clinica e la tollerabilità della moxifloxacina nella CAP, nelle AECB e nelle ABS sono state studiate su un numero elevato di pazienti, nel corso di diversi trial multicentrici controllati, nazionali e internazionali, strutturati nella maggior parte come studi in doppio cieco [101-118].

Le Tabelle 10 - 12 riassumono i risultati di efficacia dei principali trial clinici controllati riguardanti l'impiego della moxifloxacina orale nel trattamento rispettivamente delle CAP, delle AECB e delle ABS.

Nelle polmoniti acquisite in comunità (Tabella 10), la moxifloxacina somministrata per 10 giorni alla dose orale di $400 \mathrm{mg}$ od, ha dimo- strato un livello di efficacia clinica elevato, compreso tra il $90 \%$ e il $95 \%$ dei casi, del tutto equivalente a quello ottenuto con la somministrazione di claritromicina $500 \mathrm{mg}$ bid o di amoxicillina 1 grammo tid.

In un recente studio multicentrico internazionale il trattamento sequenziale iv/os con moxifloxacina, alla dose di $400 \mathrm{mg}$ od per un massimo di 15 giorni, è risultato significativamente superiore come efficacia ( $84 \%$ vs $74 \%$ ) rispetto ad un analogo trattamento sequenziale con amoxicillina/clavulanato, somministrata alla dose di 1,2 g tid per via endovenosa e di $625 \mathrm{mg}$ tid per via orale, eventualmente associata a claritromicina.

L'elevata efficacia clinica della moxifloxacina nella CAP è stata confermata anche in diverse ricerche cliniche condotte in aperto [105, 106].

L'efficacia clinica della moxifloxacina nelle AECB è risultata analogamente molto elevata, con percentuali di successi alla visita di controllo finale oscillante tra l' $80 \%$ e il $92 \%$. (Tabella 11)

La moxifloxacina, somministrata alla dose orale di 400mg od per 5 giorni, ha dimostrato di essere equivalente, come efficacia clinica, a trattamenti orali di 7-10 giorni con claritromicina $500 \mathrm{mg}$ bid, o a trattamenti di 5 giorni con azitromicina somministrata 4 volte al giorno, o a trattamenti di 7 giorni con amoxicillina/ clavulanato alla dose orale di $625 \mathrm{mg}$ tid.

Un recente studio multicentrico condotto in Italia su circa 500 pazienti affetti da AECB (studio SMART), ha dimostrato che la moxi-

\section{Tabella 10}

Efficacia della moxifloxacina nei pazienti con polmonite acquisita in comunità (CAP): sommario dei risultati degli studi clinici controllati randomizzati in doppio cieco di confronto tra moxifloxacina e claritromicina o amoxicillina o amoxicillina/clavulanato

\begin{tabular}{|c|c|c|c|c|c|c|}
\hline \multirow[t]{2}{*}{ Studio } & \multirow{2}{*}{$\begin{array}{l}\text { N. pazienti } \\
\text { arruolati }\end{array}$} & \multirow[t]{2}{*}{ Trattamenti e posologie } & \multicolumn{3}{|c|}{$\%$ Successi } & \multirow{2}{*}{$\begin{array}{l}\text { Risultato del } \\
\text { confronto }\end{array}$} \\
\hline & & & Eradicazione & Clinici & Follow-up & \\
\hline \multirow{2}{*}{$\begin{array}{l}\text { Fogarty et al. } 1999 \\
{[101]}\end{array}$} & \multirow[t]{2}{*}{474} & MOX 400mg os od x $10 \mathrm{gg}$ & $97 \%$ & $91 \%$ & $95 \%$ & \multirow[t]{2}{*}{$\mathrm{MOX}=\mathrm{CLR}$} \\
\hline & & CLR 500mg os bid x 10gg & $96 \%$ & $92 \%$ & $95 \%$ & \\
\hline \multirow{3}{*}{$\begin{array}{l}\text { Hoffken et al. } 2001 \\
\text { [102] }\end{array}$} & \multirow[t]{3}{*}{678} & MOX $200 \mathrm{mg}$ os od x $10 \mathrm{gg}$ & $72,5 \%$ & $93,9 \%$ & $90,7 \%$ & \multirow{3}{*}{$\begin{array}{l}\operatorname{MOX} 200= \\
\operatorname{MOX} 400=C L R\end{array}$} \\
\hline & & MOX 400mg os od x $10 \mathrm{gg}$ & $78,7 \%$ & $94,4 \%$ & $92,8 \%$ & \\
\hline & & CLR 500mg os bid x 10gg & $70,7 \%$ & $94,3 \%$ & $92,2 \%$ & \\
\hline \multirow{2}{*}{$\begin{array}{l}\text { Petipretz et al. } 2001 \\
\text { [103] }\end{array}$} & \multirow[t]{2}{*}{411} & MOX 400mg os od x 10gg & $89,7 \%$ & $91,5 \%$ & $89,4 \%$ & \multirow[t]{2}{*}{$\mathrm{MOX}=\mathrm{AMX}$} \\
\hline & & AMX $1000 \mathrm{mg}$ os tid $\times 10 \mathrm{gg}$ & $82,4 \%$ & $89,7 \%$ & $89,3 \%$ & \\
\hline \multirow[t]{2}{*}{$\begin{array}{l}\text { Finch et al. } 2002 \\
{[104]}\end{array}$} & \multirow[t]{2}{*}{628} & $\begin{array}{l}\text { Sequenziale MOX 400mg } \\
\text { iv/os od x 7-14gg }\end{array}$ & $93,7 \%$ & $93,4 \%$ & $83,7 \%$ & \multirow[t]{2}{*}{$\mathrm{MOX}>$ Co-AMX } \\
\hline & & $\begin{array}{l}\text { Sequenziale Co-AMX 1,2g } \\
\text { iv/ } 625 \mathrm{mg} \text { os tid x } 7-14 \mathrm{gg} \\
\text { (CLR 500mg iv/os)* }\end{array}$ & $81,7 \%$ & $85,4 \%$ & $74,3 \%$ & \\
\hline
\end{tabular}

MOX: moxifloxacina; CLR: claritromicina; AMX: amoxicillina; Co-AMX: Amoxicillina/clavulanato

* Aggiunta di claritromicina opzionale a discrezione del medico

- Differenza statisticamente significativa per il numero di successi clinici e batteriologici (è stata osservata anche una minore

mortalità ed una migliore tollerabilità nel gruppo trattato con moxifloxacina) 
floxacina, somministrata alla dose di 400mg od per soli 5 giorni, è efficace quanto un trattamento intramuscolare con ceftriaxone somministrato alla dose di 1 grammo una volta al giorno [111].

L'efficacia e l'utilità cliniche della moxifloxacina nelle bronchiti croniche riacutizzate sono state confermate da alcuni studi condotti in aperto [112-114].

Eccellente efficacia clinica ha evidenziato la moxifloxacina anche nel trattamento delle sinusiti acute batteriche, con percentuali di successi alla visita di controllo oscillanti tra 1'86\% e il 97\% (Tabella 12).

La moxifloxacina, somministrata per via orale alla dose di 400mg od per 7 giorni, è risultata significativamente più efficace alla fine del trattamento, rispetto ad un trattamento con cefuroxim-axetil somministrato per 10 giorni alla dose orale di 250mg bid. Dieci giorni di terapia con moxifloxacina 400mg od sono risultati equivalenti, come efficacia, a dieci giorni di terapia con amoxicillina/clavulanato alla dose orale di $875 \mathrm{mg}$ bid.

La moxifloxacina ha dimostrato un' efficacia clinica equivalente a quella della trovafloxacina, ma con minori effetti collaterali e un minor numero di abbandoni per reazioni avverse [118].

L'insieme degli studi clinici controllati disponibili in letteratura documenta un' efficacia clinica elevata della moxifloxacina orale nelle infezioni delle basse ed alte vie respiratorie, con percentuali di successi compresi mediamente tra il $90 \%$ e il $95 \%$.
Il successo clinico della moxifloxacina è strettamente correlato con il successo batteriologico, come dimostra la Tabella 13 [9]. Infatti, considerando cumulativamente tutti i casi in cui si è potuto isolare un patogeno e valutare l'efficacia batteriologica, è stato possibile evidenziare una stretta correlazione tra percentuali di eradicazione e percentuali di guarigioni cliniche. Dopo un trattamento orale con moxifloxacina alle dosi terapeutiche usuali, le percentuali di eradicazione dei principali patogeni respiratori oscillavano tra il $90 \%$ e il $100 \%$ e scendevano al $67 \%$ solo nel caso di Pseudomonas aeruginosa, batterio comunque poco rilevante per la patogenesi delle infezioni acquisite in comunità, nei confronti del quale la moxifloxacina anche in vitro dimostra una insufficiente attività battericida.

\section{TOLLERABILITÀ EPROFILO DISICUREZZA}

La moxifloxacina è un fluorochinolone dotato di un'eccellente tollerabilità clinica [119130]. L'analisi delle reazioni avverse, registrate nel corso degli studi clinici controllati, condotti in cieco o in aperto, e nel corso della farmacovigilanza post-marketing, evidenzia un profilo di tollerabilità e di sicurezza della moxifloxacina sovrapponibile a quello dei farmaci coi quali è stato confrontato [98].

Una recente rassegna di 26 studi clinici comparativi, effettuata per valutare la sicurez-

\section{Tabella 11}

Efficacia della moxifloxacina nei pazienti con episodi di riacutizzazione della bronchite cronica (AECB): sommario dei risultati degli studi clinici controllati randomizzati di confronto tra moxifloxacina e claritromicina o azitromicina o ceftriaxone

\begin{tabular}{|c|c|c|c|c|c|c|c|}
\hline \multirow[t]{3}{*}{ Studio } & \multirow{3}{*}{$\begin{array}{l}\text { N. pazienti } \\
\text { arruolati }\end{array}$} & \multirow[t]{3}{*}{ Trattamenti e posologie } & \multicolumn{4}{|c|}{$\%$ Successi valutabili per efficacia } & \multirow{3}{*}{$\begin{array}{c}\text { Risultato } \\
\text { dei confronti }\end{array}$} \\
\hline & & & \multicolumn{2}{|c|}{ Clinici } & \multicolumn{2}{|c|}{ Batteriologici } & \\
\hline & & & Fine terapia & TOC & Fine terapia & TOC & \\
\hline \multirow{3}{*}{$\begin{array}{l}\text { Chodosh et al. } 1999 \\
\text { [107] }\end{array}$} & \multirow[t]{3}{*}{936} & MOX 400mg os od x 5gg & $94 \%$ & $94 \%$ & $94 \%$ & $89 \%$ & \multirow{3}{*}{$\begin{array}{l}\text { MOX5gg = } \\
\text { MOX10gg = } \\
\text { CLR10gg }\end{array}$} \\
\hline & & MOX 400mg os od x $10 \mathrm{gg}$ & $94 \%$ & $96 \%$ & $95 \%$ & $91 \%$ & \\
\hline & & CLR 500mg os bid x 10gg & $95 \%$ & $96 \%$ & $91 \%$ & $85 \%$ & \\
\hline \multirow{2}{*}{$\begin{array}{l}\text { Wilson et al. } 1999 \\
\text { [108] }\end{array}$} & \multirow[t]{2}{*}{750} & MOX 400mg os od $\mathrm{x} 5 \mathrm{gg}$ & $89,1 \%$ & $89,2 \%$ & $77,4 \%$ & $79,8 \%$ & \multirow{2}{*}{$\begin{array}{l}\text { MOX5gg = } \\
\text { CLR7gg }\end{array}$} \\
\hline & & CLR 500mg os bid x 7gg & $88,4 \%$ & $88,9 \%$ & $62,3 \%$ & $77,5 \%$ & \\
\hline \multirow{2}{*}{$\begin{array}{l}\text { DeAbate et al. } 2000 \\
\text { [109] }\end{array}$} & \multirow[t]{2}{*}{567} & MOX 400mg os od x $5 \mathrm{gg}$ & $91 \%$ & $88 \%$ & $95 \%$ & $89 \%$ & \multirow{2}{*}{$\begin{array}{l}\text { MOX5gg = } \\
\text { AZT5gg }\end{array}$} \\
\hline & & $\begin{array}{l}\text { AZT 500mg os qid } \times 1 \mathrm{~g}+ \\
\text { AZT250mg os qid } \times 4 \mathrm{gg}\end{array}$ & $92 \%$ & $88 \%$ & $94 \%$ & $86 \%$ & \\
\hline \multirow{2}{*}{$\begin{array}{l}\text { Schaberg et al, } \\
2001 \text { [110] }\end{array}$} & \multirow[t]{2}{*}{575} & MOX 400mg os od x 5gg & --- & $96,2 \%$ & --- & $87,7 \%$ & \multirow{2}{*}{$\begin{array}{l}\text { MOX5gg = } \\
\text { CoAMX7gg }\end{array}$} \\
\hline & & CoAMX 625mg os tid x $7 \mathrm{gg}$ & --- & $91,6 \%$ & --- & $89,6 \%$ & \\
\hline Grassi et al. (Studio & \multirow[t]{2}{*}{476} & MOX 400mg os od x $5 \mathrm{gg}$ & $95,3 \%$ & $90,6 \%$ & --- & $91,7 \%$ & \multirow{2}{*}{$\begin{array}{l}\text { MOX5gg = } \\
\text { CFTX7gg }\end{array}$} \\
\hline SMART) 2002 [111] & & CFTX $1 \mathrm{~g}$ im od $\mathrm{x} 7 \mathrm{gg}$ & $92,9 \%$ & $89,0 \%$ & --- & $93,3 \%$ & \\
\hline
\end{tabular}

MOX: moxifloxacina; CLR: claritromicina; AZT: azitromicina; CoAMX: Amoxicillina/clavulanato; CFTX: ceftriaxone 


\begin{tabular}{|c|c|c|c|c|c|c|}
\hline \multirow[t]{3}{*}{ Studio } & \multirow{3}{*}{$\begin{array}{l}\text { N. pazienti } \\
\text { arruolati }\end{array}$} & \multirow[t]{3}{*}{ Trattamenti e posologie } & \multicolumn{3}{|c|}{$\%$ Successi } & \multirow{3}{*}{$\begin{array}{l}\text { Risultato dei } \\
\text { confronti }\end{array}$} \\
\hline & & & \multicolumn{2}{|c|}{ Clinici } & \multirow{2}{*}{$\begin{array}{c}\text { Batteriologici } \\
\text { Fine terapia }\end{array}$} & \\
\hline & & & Fine terapia & Follow-up & & \\
\hline \multirow{2}{*}{$\begin{array}{l}\text { Burke et al, } 1999 \\
{[115]}\end{array}$} & \multirow[t]{2}{*}{542} & MOX 400mg os od x $10 \mathrm{gg}$ & $90 \%$ & $90 \%$ & $\tilde{\mathrm{N}} \tilde{N}$ & $\operatorname{MOX} 10 \mathrm{gg}=$ \\
\hline & & CFAX 250mg os bid x 10gg & $89 \%$ & $89 \%$ & $\tilde{N} \tilde{N}$ & CFAX10gg \\
\hline \multirow{2}{*}{$\begin{array}{l}\text { Siegert et al, } 2000 \\
{[116]}\end{array}$} & \multirow[t]{2}{*}{493} & MOX 400mg os od x $7 \mathrm{gg}$ & $96,7 \%$ & $90,7 \%$ & $94,5 \%$ & MOX7gg > \\
\hline & & CFAX 250mg os bid x $10 \mathrm{gg}$ & $90,7 \%$ & $89,2 \%$ & $83,5 \%$ & CFAX10gg \\
\hline \multirow{2}{*}{$\begin{array}{l}\text { Rakkar et al. } 2001 \\
\text { [117] }\end{array}$} & \multirow[t]{2}{*}{475} & MOX 400mg os od x 10gg & $86 \%$ & $\tilde{\mathrm{N}}-$ & $\tilde{\mathrm{N}}-$ & $\operatorname{MOX} 10 \mathrm{gg}=$ \\
\hline & & CoAMX 875mg os bid x 10gg & $84 \%$ & $\tilde{\mathrm{N}}-$ & $\tilde{\mathrm{N}}-$ & CoAMX10gg \\
\hline \multirow{2}{*}{$\begin{array}{l}\text { Klossek et al, } 2000 \\
{[118]}\end{array}$} & \multirow[t]{2}{*}{452} & MOX 400mg os od x 7gg & $96,9 \%$ & $94,9 \%$ & $94,4 \%$ & MOX7gg $=$ \\
\hline & & TROV 200mg os od x $10 \mathrm{gg}$ & $92,1 \%$ & $97,6 \%$ & $90,1 \%$ & TROV10gg \\
\hline
\end{tabular}

MOX: moxifloxacina; CFAX: cefuroxim-axetil; CoAMX: Amoxicillina/clavulanato, TROV : trovafloxacina

\section{Tabella 12}

Efficacia della moxifloxacina nei pazienti affetti da sinusiti acute batteriche (ABS): sommario dei risultati degli studi clinici controllati randomizzati di confronto tra moxifloxacina e cefuroxim-axetil o amoxicillina/clavulanato

za della moxifloxacina, somministrata alla dose di 400mg od per 5 giorni, includeva complessivamente 6.178 pazienti trattati con moxifloxacina e 4.809 pazienti trattati con un farmaco di confronto: le percentuali di pazienti con reazioni avverse e con reazioni avverse gravi sono risultate sovrapponibili nel gruppo trattato con moxifloxacina e nel gruppo di confronto (Tabella 14).

Anche i dati di farmacovigilanza postmarketing condotta in Germania su 5.805 pazienti dimostrano un' ottima tollerabilità e sicurezza [98].

I dati di farmacovigilanza sui fluorochinoloni recentemente pubblicati in Italia con- fermano la buona tollerabilità della moxifloxacina [130].

La Tabella 15 evidenzia che il tipo e la frequenza delle reazioni avverse più comunemente osservate nei pazienti trattati con moxifloxacina non sono differenti da quelli osservati nei pazienti trattati con i farmaci di confronto [98].

La moxifloxacina non causa danni epatici: alterazioni di qualche test di funzionalità epatica (aumento delle transaminasi e/o della bilirubuna oltre i valori di normalità) sono state osservate nello $0,9 \%$ dei soggetti trattati con moxifloxacina contro l' $1,1 \%$ dei casi trattati con gli altri farmaci.

\begin{tabular}{|c|c|c|c|c|c|c|}
\hline \multirow[t]{2}{*}{ Patogeno } & \multirow{2}{*}{$\begin{array}{l}\text { MIC modale } \\
\text { (range) } \mathrm{mg} / \mathrm{L}\end{array}$} & \multirow{2}{*}{$\begin{array}{c}\text { Trattati n } \\
(\%)\end{array}$} & \multicolumn{2}{|c|}{ Risposta batteriologica } & \multicolumn{2}{|c|}{ Risposta clinica } \\
\hline & & & $\begin{array}{c}\text { Eradicazioni } \\
\%\end{array}$ & $\begin{array}{c}\text { Persistenza } \\
\%\end{array}$ & $\begin{array}{c}\text { Successi } \\
\%\end{array}$ & $\begin{array}{c}\text { Insuccessi } \\
\%\end{array}$ \\
\hline $\begin{array}{l}\text { Streptococcus } \\
\text { pneumonite }\end{array}$ & $\begin{array}{c}0,26 \\
(0,002-1)\end{array}$ & $\begin{array}{c}321 \\
(26 \%)\end{array}$ & 92 & 5 & 93 & 7 \\
\hline $\begin{array}{c}\text { Haemophilus } \\
\text { influenzae }\end{array}$ & $\begin{array}{c}0,064 \\
(0,002-1)\end{array}$ & $\begin{array}{c}273 \\
(22 \%)\end{array}$ & 97 & 2 & 95 & 4 \\
\hline $\begin{array}{l}\text { Moraxella } \\
\text { catarrhalis }\end{array}$ & $\begin{array}{c}0,125 \\
(0,008-0,25)\end{array}$ & $\begin{array}{c}148 \\
(12 \%)\end{array}$ & 93 & 4 & 92 & 8 \\
\hline $\begin{array}{l}\text { Staphylococcus } \\
\text { aureus }\end{array}$ & $\begin{array}{c}0,125 \\
(0,032-4)\end{array}$ & $\begin{array}{c}85 \\
(7 \%)\end{array}$ & 99 & 1 & 97 & 3 \\
\hline $\begin{array}{l}\text { Haemophilus } \\
\text { parainfluenzae }\end{array}$ & $\begin{array}{c}0,125 \\
(0,002-1)\end{array}$ & $\begin{array}{c}78 \\
(6 \%)\end{array}$ & 99 & 1 & 100 & 0 \\
\hline $\begin{array}{l}\text { Klebsiella } \\
\quad \text { pneumoniae }\end{array}$ & $\begin{array}{c}0,125 \\
(0,032-1)\end{array}$ & $\begin{array}{c}65 \\
(5 \%)\end{array}$ & 90 & 8 & 91 & 9 \\
\hline $\begin{array}{l}\text { Escherichia } \\
\text { coli }\end{array}$ & $\begin{array}{c}0,064 \\
(0,016-0,125)\end{array}$ & $\begin{array}{c}17 \\
(1 \%)\end{array}$ & 94 & 6 & 94 & 6 \\
\hline $\begin{array}{c}\text { Enterobacter } \\
\text { cloacae }\end{array}$ & $\begin{array}{c}0,125 \\
(0,064-0,5)\end{array}$ & $\begin{array}{c}20 \\
(2 \%)\end{array}$ & 100 & 0 & 95 & 5 \\
\hline $\begin{array}{c}\text { Pseudomonas } \\
\text { aeruginosa }\end{array}$ & $\begin{array}{c}2,0 \\
(0,016-32)\end{array}$ & $\begin{array}{c}39 \\
(3 \%)\end{array}$ & 67 & 33 & 77 & 23 \\
\hline
\end{tabular}

\section{Tabella 13}

Correlazione tra risultati batteriologicie clinici ottenuti con moxifloxacina (400mg/die) in studi clinici controllati nelle infezioni delle vie respiratorie (modificato da: Kraseman et al, 2001) [9] 


\section{Tabella 14}

Sommario delle reazioni avverse registrate nel corso di 26 studi clinici controllati comparativi e della farmacovigilanza post-marketing attuata in Germania sulla moxifloxacina finoal febbraio 2000 (modificata da: Talan, 2001) [98]

\section{Tabella 15}

Reazioni avverse più frequenti (incidenza $>1 \%$ ) alla moxifloxacina e agli antibiotici di confronto osservate in 26 trial clinici controllati comparativi (modificata da: Talan, 2001) [98]

\begin{tabular}{|c|c|c|c|}
\hline Risultati & $\begin{array}{r}26 \text { Stud } \\
\text { Moxifloxacina } \\
(\mathrm{n}=6178)\end{array}$ & $\begin{array}{l}\text { i Clinici } \\
\text { Comparatori* } \\
(n=4809)\end{array}$ & $\begin{array}{c}\text { Farmacovigilanza } \\
\text { Post-marketing (Germania) } \\
\text { Moxifloxacina }(\mathrm{n}=5805)\end{array}$ \\
\hline Pazienti con Eventi Avversi & $2800(45 \%)$ & $2088(43 \%)$ & $261(5 \%)$ \\
\hline $\begin{array}{l}\text { Pazienti con Reazioni Avverse } \\
\text { al Farmaco }\end{array}$ & $1619(26 \%)$ & $1129(23 \%)$ & $119(2 \%)$ \\
\hline $\begin{array}{l}\text { Pazienti con Reazioni Avverse } \\
\text { Gravi al Farmaco }\end{array}$ & $34(<1 \%)$ & $33(<1 \%)$ & $14(<1 \%)$ \\
\hline $\begin{array}{l}\text { Sospensioni premature causate } \\
\text { da Reazioni Avverse al Farmaco }\end{array}$ & $186(3 \%)$ & $157(3 \%)$ & $68(1 \%)$ \\
\hline Morti & $16(<1 \%)$ & $18(<1 \%)$ & $3(<1 \%)$ \\
\hline
\end{tabular}

*Nei diversi trials come farmaci di confronto sono stati impiegati: cefuroxim axetil, cefalessina, claritromicina, azitromicina, amoxicillina, amoxicillina/clavulanato, ofloxacina e trovafloxacina.
La moxifloxacina, come effetto di classe, tende ad allungare il tratto QT, mediante un'interferenza con i canali del potassio. Questo effetto, tuttavia, quando si è manifestato nei soggetti trattati con moxifloxacina, non ha mai dato origine a reazioni cardiache avverse clinicamente rilevanti o a casi di morte da torsione di punta [124-129].

In una ricerca su 2.650 pazienti studiati con un tracciato ECGrafico, il prolungamento del tratto QT nei soggetti trattati con moxifloxacina è stato osservato nel $2,8 \%$ dei casi con incrementi considerati entro limiti non pericolosi (media corretta del prolungamento $6 \pm 26 \mathrm{~ms}$ ), valori leggermente inferiori a quelli riscontrati nei soggetti trattati con claritromicina, dove il $3,7 \%$ dei casi ha manifestato un incremento medio del tratto QT di $2 \pm 23 \mathrm{~ms}$, e molto simili a quelli osservati nei soggetti trattati con gli altri farmaci di confronto (Tabella 14), dove il 2,2\% dei casi ha manifestato un incremento medio di $1 \pm 23 \mathrm{~ms}$ [119].
La moxifloxacina, a differenza di altri fluorochinoloni, non presenta rischi di fototossicità e fotosensibilizzazione [121, 122].

\section{CONSIDERAZIONI FARMACOECONOMICHE}

Le caratteristiche microbiologiche, farmacocinetiche, farmacodinamiche della moxifloxacina e il suo profilo clinico di efficacia, tollerabilità e sicurezza possono influenzare in modo positivo la formazione dei costi sanitari e sociali delle infezioni delle vie respiratorie, producendo un sensibile risparmio di risorse pubbliche e private.

La disponibilità di terapie antibiotiche caratterizzate da un migliore rapporto costo/efficacia, soprattutto per trattare le patologie più frequenti e con maggior impatto sociale, come $\mathrm{CAP}$ e $\mathrm{AECB}$, è una necessità sempre più sentita dai decisori che hanno la responsabilità di

\begin{tabular}{lcc}
\hline Reazione Avversa & $\begin{array}{c}\text { Moxifloxacina 400mg/die } \\
(\mathbf{n}=\mathbf{6 1 7 8})\end{array}$ & $\begin{array}{c}\text { Comparatori* } \\
(\mathbf{n}=\mathbf{4 8 0 9})\end{array}$ \\
\hline Nausea & $477(8 \%)$ & $255(5 \%)$ \\
Diarrea & $344(6 \%)$ & $221(5 \%)$ \\
Vertigine & $178(3 \%)$ & $120(2 \%)$ \\
Dolori addominali & $112(2 \%)$ & $74(2 \%)$ \\
Cefalea & $106(2 \%)$ & $102(2 \%)$ \\
Vomito & $105(2 \%)$ & $80(2 \%)$ \\
Dispepsia & $75(1 \%)$ & $48(<1 \%)$ \\
Secchezza delle fauci & $64(1 \%)$ & $19(<1 \%)$ \\
Gusto cattivo & $58(<1 \%)$ & $90(2 \%)$ \\
Test di funzionalità epatica anormali & $54(<1 \%)$ & $51(1 \%)$ \\
\hline
\end{tabular}

*Nei diversi trials come farmaci di confronto sono stati impiegati: cefuroxim axetil, cefalessina, claritromicina, azitromicina, amoxicillina, amoxicillina/clavulanato, ofloxacina e trovafloxacina. 
gestire il SSN. La moxifloxacina è un nuovo fluorochinolone orale che si propone come uno strumento altamente conveniente per il SSN e per la società perché dotato di un vantaggioso rapporto costo/efficacia.

L'efficacia della moxifloxacina orale nelle infezioni delle basse e alte vie respiratorie è massimale e può essere considerata almeno equivalente a quella ottenibile con i classici protocolli terapeutici che prevedono l'utilizzo di una betalattamina, come l'amoxicillina/ clavulanato, o di una cefalosporina orale, o di un macrolide, come la claritromicina o l'azitromicina, oppure, infine, di ceftriaxone per via intramuscolare.

L'equivalente efficacia terapeutica con i farmaci di confronto consente di semplificare l'analisi farmacoeconomica e di riportare l'analisi costo/efficacia alla tecnica della minimizzazione dei costi. Possiamo quindi esaminare quali caratteristiche microbiologiche, farmacologiche e cliniche della moxifloxacina sono teoricamente importanti per ridurre i costi sanitari e sociali del trattamento antibiotico delle infezioni delle vie respiratorie.

L'elevata sensibilità alla moxifloxacina dei patogeni respiratori, la quasi totale biodisponibilità orale e la lunga emivita di questo fluorochinolone sono fattori che, consentendo di ottenere ottimi risultati clinici con una sola dose giornaliera di $400 \mathrm{mg}$ per via orale, comportano anche un risparmio sui costi di acquisto del farmaco e sui costi di somministrazione. La via orale, infatti, oltre ad essere di facile praticabilità da parte dello stesso paziente, non richiede i costi aggiuntivi dovuti ai materiali e al lavoro del personale infermieristico necessari per preparare e somministrare un prodotto per via parenterale.

Caratteristica fondamentale della moxifloxacina è la sua rapidità d'azione che, nel caso della AECB, si traduce nella possibilità di ridurre il numero di giorni di terapia dagli usuali 7-10 a 5, con significativi risparmi sulla quantità di antibiotico consumato.

La rapidità dell'effetto battericida, la ridotta tendenza a selezionare ceppi resistenti e la stretta correlazione tra eradicazione e successi clinici può comportare altre ricadute sanitarie importanti, come una riduzioni delle morti da CAP o da AECB entro un mese dalla fine del trattamento antibiotico o la riduzione del numero di ricoveri come esito di CAP e AECB. Queste ricadute positive correlabili all'uso della moxifloxacina nel trattamento delle infezioni delle vie respiratorie sono state documentate in una recente analisi post-hoc effettuata su 8 studi clinici controllati comparativi (Tabella 16) [98].

L'elevata probabilità di successo clinico e batteriologico, la rapidità della guarigione, la buona tollerabilità consentono di ridurre anche i costi delle visite mediche ambulatoriali e domiciliari, i costi degli esami di laboratorio e strumentali, nonché eventuali altri costi diretti sanitari e non sanitari a carico del SSN e del paziente.

A margine dello studio SMART è stata effettuata un' analisi minimizzazione dei costi nella prospettiva del SSN e della società, mettendo a confronto un trattamento breve di 5 giorni con moxifloxacina orale $400 \mathrm{mg}$ od con un trattamento di 7 giorni con ceftriaxone intramuscolare alla dose di 1 grammo od [111]. I principali risultati di tale analisi sono riassunti nella Tabella 17.

Secondo questa analisi, per ogni episodio di AECB il SSN potrebbe risparmiare oltre 262 euro e la società oltre 448 euro qualora venisse usata la moxifloxacina invece del ceftriaxone. I risparmi più consistenti potrebbero essere sul costo di acquisto e somministrazione dell'antibiotico, sul costo degli accertamenti diagnostici e soprattutto sul costo ospedaliero.

La rapidità d'azione e la possibilità di ottenere guarigioni durature con un minor numero di giorni di terapia antibiotica può comportare significativi risparmi anche sui costi indiretti dovuti alla perdita di produttività dei pazienti affetti da bronchite cronica in età lavorativa. Nell' analisi condotta in Italia sullo studio SMART la perdita di ore di lavoro del paziente o dei familiari è stata lievemente superiore nei soggetti trattati con ceftriaxone ed è stato stimato che l'uso di moxifloxacina potrebbe comportare un risparmio di circa 30 euro per ogni episodio di AECB trattato.

\begin{tabular}{lccccc}
\hline Risultati & \multicolumn{2}{c}{ Moxifloxacina } & \multicolumn{2}{c}{ Comparatori* } & P \\
& n/totale & $\%$ & n/totale & $\%$ & \\
& & & & & \\
\hline $\begin{array}{l}\text { Morti come esito di CAP avvenute entro } \\
\quad 30 \text { giomi da fine trattamento }\end{array}$ & $4 / 701$ & $0,57 \%$ & $12 / 705$ & $1,70 \%$ & 0,045 \\
$\begin{array}{c}\text { Morti come esito di AECB avvenute } \\
\quad \text { entro 30 giorni da fine trattamento }\end{array}$ & $1 / 1224$ & $0,08 \%$ & $3 / 924$ & $0,32 \%$ & 0,196 \\
Ricoveri come esito di CAP e AECB & $18 / 1925$ & $0,94 \%$ & $30 / 1629$ & $1,84 \%$ & 0,020 \\
\hline
\end{tabular}

CAP: polmonite acquisita in comunità; AECB: riacutizzazione della bronchite cronica.

* Amoxicillina e amoxicillina/clavulanato nelle CAP; claritromicina, cefixime e cefuroxime nelle AECB

\section{Tabella 16}

Confronto post-hoc di morti e ricoveri ospedalieri registrati nel corso di 8 trial clinici controllati come esito di CAP e AECB nei gruppi trattaticon moxifloxacina e nei gruppi trattaticon antibiotici di confronto (modificata da: Talan 2001)[98] 


\section{Tabella 17}

Costi delle risorse sanitarie e non sanitarie impiegate mediamente in un episodio di riacutizzazione della bronchite cronica (AECB) nei pazienti trattaticon moxifloxacina orale (400mg od $x 5$ giorni) o con ceftriaxone intramuscolare (1g od $x 7$ giorni), nelle prospettive del Servizio Sanitario Nazionale (SSN) e della società (SOC)

(modificata da: Grassi et al, 2002)[111]

\begin{tabular}{|c|c|c|c|c|c|c|}
\hline \multirow[t]{3}{*}{ Parametro di costo } & \multicolumn{6}{|c|}{ Costo medio/paziente/episodio AECB* } \\
\hline & \multicolumn{2}{|c|}{ Moxifloxacina } & \multicolumn{2}{|c|}{ Ceftriaxone } & \multicolumn{2}{|c|}{ Differenza } \\
\hline & SSN & SOC & SSN & SOC & SSN & SOC \\
\hline Antibiotici* & & 25,82 & & 140,99 & & $-115,17$ \\
\hline Altri farmaci* & & 18,54 & & 14,92 & & 3,62 \\
\hline Accertamenti diagnostici* & & 149,96 & & 201,62 & & $-51,66$ \\
\hline Visite ambulatoriali* & & 2,50 & & 1,80 & & 0,70 \\
\hline Ospedale e day-hospital* & 1796,46 & 2152,02 & 1896,61 & 2408,03 & $-100,15$ & $-256,01$ \\
\hline Perdita lavoro* & & 26,59 & & 56,3 & & $-29,71$ \\
\hline Totale Costo* & 1993,28 & 2375,43 & 2255,94 & 2823,66 & $-262,66$ & $-448,23$ \\
\hline
\end{tabular}

Un recente studio condotto negli Stati Uniti ha dimostrato che la maggiore rapidità di risoluzione di un episodio di riacutizzazione della bronchite cronica dovuta al trattamento con moxifloxacina, in confronto con levofloxacina, ha comportato un risparmio medio sui costi indiretti per episodio/paziente di circa 242 dollari [131]. Tale differenza era dovuta essenzialmente alla minore perdita di produttività sul lavoro durante la prima fase di ripresa dell' attività lavorativa di un bronchitico cronico dopo un episodio di riacutizzazione.

Considerando il numero medio di episodi annuali di riacutizzazione, il risparmio annuale per paziente sui costi indiretti potrebbe essere di oltre 725 dollari, una cifra non trascurabile per la società e per il sistema di sicurezza sociale.

\section{CONCLUSIONE}

I dati disponibili indicano che la moxifloxacina orale alla dose di 400mg od è un ottimo candidato per la monoterapia delle esacerbazioni di bronchite cronica e delle polmoniti acquisite in comunità, soprattutto nei casi gestibili a domicilio o con ricoveri brevi e successiva terapia domiciliare. La rapidità d'azione, la monosomministrazione orale giornaliera, l'elevata efficacia clinica e batteriologica anche a cicli brevi di 5 giorni e il buon profilo di tollerabilità sono i principali fattori che garantiscono un vantaggioso rapporto costo/efficacia alla moxifloxacina in confronto con tutte le altre alternative oggi disponibili.

\section{BIBLIOGRAFIA}

1. Balfour JA, Wiseman LR. Moxifloxacin. Drugs 57:363-73; 1999

2. Balfour JA, Lamb HM. Moxifloxacin: a review of its clinical potential in the management of community-acquired respiratory tract infections. Drugs. 59:115-39, 2000.

3. Ball P. Moxifloxacin (Avelox): an 8-methoxyquinolone antibacterial with enhanced potency. Int J Clin Pract. 54:329-32, 2000 .

4. Barrett JF. Moxifloxacin Bayer. Curr Opin Invest Drugs. 1:45-51, 2000.

5. Culley CM, Lacy MK, Klutman N, Edwards B. Moxifloxacin: clinical efficacy and safety. Am J Health-System Pharm. 58:379-88, 2001.

6. Lode H. Focus on Moxifloxacin. "Nosocomial Infections Today", 3rd Int Symp, Congres Report, GIMMOC Vol V C\&M 2: 1-12, 2001.

7. Blondeau JM, Hansen GT. Moxifloxacin: a review of the microbiological, pharmacological, clinical and safety features. Exp Opin Pharmacother. 2:317-35, 2001.

8. Blondeau JM. A review of the comparative in-vitro activities of 12 antimicrobial agents, with a focus on five new respiratory quinolones'. J Antimicrob Chemother 43 Suppl B:1-11, 1999. 
9. Krasemann C, Meyer J, Tillotson G. Evaluation of the clinical microbiology profile of moxifloxacin. Clin Infect Dis 32 Suppl 1:S51-63, 2001.

10. Dalhoff A, Krasemann C, Wegener S, et al. Penicillin-resistant streptococcus pneumoniae: review of moxifloxacin activity. Clin Infect Dis 32 Suppl 1:S22-9, 2001.

11. Blondeau JM, Laskowski R, Bjarnason J, et al. Comparative in vitro activity of gatifloxacin, grepafloxacin, levofloxacin, moxifloxacin and trovafloxacin against 4151 Gram-negative and Gram-positive organisms. Int $\mathrm{J}$ Antimicrob Agents 14:45-50, 2000.

12. Hoogkamp-Korstanje JA, Roelofs-Willemse J. Comparative in vitro activity of moxifloxacin against Gram-positive clinical isolates. J Antimicrob Chemother 45:31-9, 2000.

13. Hardy D, Amsterdam D, Mandell LA, et al. Comparative in vitro activities of ciprofloxacin, gemifloxacin, grepafloxacin, moxifloxacin, ofloxacin, sparfloxacin, trovafloxacin, and other antimicrobial agents against bloodstream isolates of gram-positive cocci. Antimicrob Agents Chemother 44:802-5, 2000.

14. Johnson AP, Warner M, George RC, et al. Activity of moxifloxacin against clinical isolates of Streptococcus pneumoniae from England and Wales. J Antimicrob Chemother 47:411-5, 2001.

15. Saravolatz L, Manzor O, Check C, et al. Antimicrobial activity of moxifloxacin, gatifloxacin and six fluoroquinolones against Streptococcus pneumoniae. J Antimicrob Chemother 47:875-7, 2001.

16. Esposito S, Noviello S, Ianniello F. Activity of moxifloxacin and twelve other antimicrobial agents against 216 clinical isolates of Streptococcus pneumoniae. Chemother 47:90-6, 2001.

17. Critchley IA, Sahm DF, Thornsberry C, et al. Antimicrobial susceptibilities of Streptococcus pyogenes isolated from respiratory and skin and soft tissue infections: United States LIBRA surveillance data from 1999. Diagn Microbiol Infect Dis 42:129-35, 2002.

18. Jonas D, Engels I, Friedhoff C, et al. Efficacy of moxifloxacin, trovafloxacin, clinafloxacin and levofloxacin against intracellular Legionella pneumophila. J Antimicrob Chemother 47:147-52, 2001.

19. Gomez-Lus R, Adrian F, del Campo R, et al. Comparative in vitro bacteriostatic and bactericidal activity of trovafloxacin, levofloxacin and moxifloxacin against clinical and environmental isolates of Legionella spp. Int J Antimicrob Agents 18:49-54, 2001.

20. Hamamoto K, Shimizu T, Fujimoto N, et al. In vitro activities of moxifloxacin and other fluoroquinolones against Mycoplasma pneumoniae. Antimicrob Agents Chemother 45:1908-10, 2001.

21. Kenny GE, Cartwright FD. Susceptibilities of Mycoplasma hominis, M. pneumoniae, and Ureaplasma urealyticum to GAR-936, dalfopristin, dirithromycin, evernimicin, gatifloxacin, linezolid, moxifloxacin, quinupristindalfopristin, and telithromycin compared to their susceptibilities to reference macrolides, tetracyclines, and quinolones. Antimicrob Agents Chemother 45:2604-8, 2001.

22. Hammerschlag MR, Roblin PM. Microbiologic efficacy of moxifloxacin for the treatment of community-acquired pneumonia due to Chlamydia pneumoniae. Int J Antimicrob Agents 15:149-52, 2000.

23. Miyashita N, Fukano H, Yoshida K, et al. In-vitro activity of moxifloxacin and other fluoroquinolones against Chlamydia species. J Infect Chemother 8:115-7, 2002.

24. MacGowan AP, Bowker KE, Holt HA, et al. Bay 12-8039, a new 8-methoxy-quinolone: comparative in-vitro activity with nine other antimicrobials against anaerobic bacteria. J Antimicrob Chemother 40:503-9, 1997.

25. Edlund C, Sabouri S, Nord CE. Comparative in vitro activity of BAY 12-8039 and five other antimicrobial agents against anaerobic bacteria. Eur J Clin Microbiol Infect Dis 17:193-5, 1998.

26. Betriu C, Gomez M, Palau ML, et al. Activities of new antimicrobial agents (trovafloxacin, moxifloxacin, sanfetrinem, and quinupristin-dalfopristin) against Bacteroides fragilis group: comparison with the activities of 14 other agents. Antimicrob Agents Chemother 43:2320-2, 1999.

27. Schaumann R, Ackermann G, Pless B, et al. In vitro activities of fourteen antimicrobial agents against obligately anaerobic bacteria. Int J Antimicrob Agents 16:225-32, 2000.

28. Horn R, Robson HG. Susceptibility of the Bacteroides fragilis group to newer quinolones and other standard anti-anaerobic agents. J Antimicrob Chemother 48:127-30, 2001.

29. Snydman DR, Jacobus NV, McDermott LA, et al. In vitro activities of newer quinolones against bacteroides group organisms. Antimicrob Agents Chemother. 46:3276-9, 2002.

30. Speciale A, Musumeci R, Blandino G, et al. Minimal inhibitory concentrations and time-kill determination of moxifloxacin against aerobic and anaerobic isolates. Int J Antimicrob Agents 19:111-8, 2002. 
31. Deshpande LM, Jones RN. Antimicrobial activity of advanced-spectrum fluoroquinolones tested against more than 2000 contemporary bacterial isolates of species causing community-acquired respiratory tract infections in the United States (1999). Diagn Microbiol Infect Dis 37:139-42, 2000.

32. Jones ME, Staples AM, Critchley I, et al. Benchmarking the in vitro activity of moxifloxacin against recent isolates of Streptococcus pneumoniae, Moraxella catarrhalis, and Haemophilus influenzae. A European multicentre study. Diagn Microbiol Infect Dis 37:203-11, 2000.

33. Esposito S, Noviello S, Ianniello F. Comparative in vitro activity of older and newer fluoroquinolones against respiratory tract pathogens. Chemother 46:309-14, 2000.

34. Cardenosa GO, Soto-Hernandez JL. In vitro activity of moxifloxacin (BAY 12-8039) against respiratory tract pathogens from six Latin-American countries. Chemother 46:379-82, 2000.

35. Blondeau JM, Vaughan D, Laskowski R, et al. Canadian Antimicrobial Study Group. Susceptibility of Canadian isolates of Haemophilus influenzae, Moraxella catarrhalis and Streptococcus pneumoniae to oral antimicrobial agents. Int J Antimicrob Agents 17:457-64, 2001.

36. Lopez H, Vilches V, Scarano S, et al. Multicentre study of the in vitro evaluation of moxifloxacin and other quinolones against community acquired respiratory pathogens. Int J Antimicrob Agents 18:379-82, 2001.

37. Decousser JW, Allouch PY, Courvalin P, et al. In vitro activity of moxifloxacin against recent community-acquired respiratory tract pathogens isolated in France: a national survey. Int J Antimicrob Agents 20:186-95, 2002.

38. Dorai-John T, Thomson CJ, Amyes SG. Moxifloxacin sensitivity of respiratory pathogens in the United Kingdom. J Chemother 14:19-24, 2002.

39. Alos JI, Oteo J, Aracil B, et al. Comparative in vitro study of the activity of moxifloxacin and other antibiotics against 150 strains of penicillin non-susceptible Streptococcus pneumoniae and against 110 strains of ampicillinresistant Haemophilus influenzae isolated in 1999-2000 in Spain. J Antimicrob Chemother 48:145-8, 2001.

40. Pong A, Thomson KS, Moland ES, et al. Activity of moxifloxacin against pathogens with decreased susceptibility to ciprofloxacin. J Antimicrob Chemother 44:621-7, 1999.

41. Johnson AP, Warner M, Livermore DM. Activity of moxifloxacin and other quinolones against pneumococci resistant to first-line agents, or with high-level ciprofloxacin resistance. Int J Antimicrob Agents 17:377-81, 2001.

42. Perez-Trallero E, Garcia-Rey C, Martin-Sanchez AM, et al. Spanish Surveillance Group for Respiratory Pathogens (SAUCE Program). Activities of six different quinolones against clinical respiratory isolates of Streptococcus pneumoniae with reduced susceptibility to ciprofloxacin in Spain. Antimicrob Agents Chemother 46:2665-7, 2002.

43. Esposito S, Noviello S, Ianniello F, et al. In vitro activity of moxifloxacin compared to other fluoroquinolones against different erythromycin-resistant phenotypes of group A beta-hemolytic streptococcus. Chemother 46:237,2000.

44. Betriu C, Redondo M, Palau ML, et al. Comparative in vitro activities of linezolid, quinupristin-dalfopristin, moxifloxacin, and trovafloxacin against erythromycin-susceptible and-resistant streptococci. Antimicrob Agents Chemother 44:1838-41, 2000.

45. Presterl E, Mueller-Uri P, Grisold A, et al. Ciprofloxacin-and methicillin-resistant staphylococcus aureus susceptible to moxifloxacin, levofloxacin, teicoplanin, vancomycin and linezolid. Eur J Clin Microbiol Infect Dis 20:486-9, 2001.

46. Jones ME, Visser MR, Klootwijk M, et al. Comparative activities of clinafloxacin, grepafloxacin, levofloxacin, moxifloxacin, ofloxacin, sparfloxacin, and trovafloxacin and nonquinolones linozelid, quinupristin-dalfopristin, gentamicin, and vancomycin against clinical isolates of ciprofloxacin-resistant and -susceptible Staphylococcus aureus strains. Antimicrob Agents Chemother 43:421-3, 1999.

47. Schouten MA, Voss A, Hoogkamp-Korstanje JA. Antimicrobial susceptibility patterns of enterococci causing infections in Europe. The European VRE Study Group. Antimicrob Agents Chemother 43:2542-6, 1999.

48. Hooper DC. Mechanisms of action of antimicrobials: focus on fluoroquinolones. Clin Inf Dis 32 (suppl 1): S9-15, 2001.

49. Schedletzky H, Wiedemann B, Heisig P. The effect of moxifloxacin on its target topoisomerases from Escherichia coli and Staphylococcus aureus. J Antimicrob Chemother 43 Suppl B:31-7, 1999.

50. Pestova E, Millichap JJ, Noskin GA, et al. Intracellular targets of moxifloxacin: a comparison with other fluoroquinolones. J Antimicrob Chemother 45:583-90, 2000.

51. Takei M, Fukuda H, Kishii R, et al. Target preference of 15 quinolones against Staphylococcus aureus, based on antibacterial activities and target inhibition. Antimicrob Agents Chemother 45:3544-7, 2001. 
52. Sanders CC. Mechanisms responsible for cross-resistance and dichotomous resistance among the quinolones. Clin Inf Dis 32 (sull 1): S1-8, 2001.

53. Piddock LJ, Johnson MM. Accumulation of 10 fluoroquinolones by wild-type or efflux mutant Streptococcus pneumoniae. Antimicrob Agents Chemother 46:813-20, 2002.

54. Jones ME, Sahm DF, Martin N, et al. Prevalence of gyrA, gyrB, parC, and parE mutations in clinical isolates of Streptococcus pneumoniae with decreased susceptibilities to different fluoroquinolones and originating from Worldwide Surveillance Studies during the 1997-1998 respiratory season. Antimicrob Agents Chemother 44:462-6, 2000.

55. Houssaye S, Gutmann L, Varon E. Topoisomerase mutations associated with in vitro selection of resistance to moxifloxacin in Streptococcus pneumoniae. Antimicrob Agents Chemother 46:2712-5, 2002.

56. Boswell FJ, Andrews JM, Jevons G, Wise R. Comparison of the in vitro activities of several new fluoroquinolones against respiratory pathogens and their abilities to select fluoroquinolone resistance. $\mathrm{J}$ Antimicrob Chemother. 50:495-502, 2002.

57. Browne FA, Clark C, Bozdogan B, et al. Single and multi-step resistance selection study in Streptococcus pneumoniae comparing ceftriaxone with levofloxacin, gatifloxacin and moxifloxacin. Int J Antimicrob Agents. 20:93-9, 2002.

58. Blondeau JM, Zhao X, Hansen G, et al. Mutant prevention concentrations of fluoroquinolones for clinical isolates of Streptococcus pneumoniae. Antimicrob Agents Chemother 45:433-8, 2001.

59. Zhanel GG, Noreddin AM. Pharmacokinetics and pharmacodynamics of the new fluoroquinolones: focus on respiratory infections. Curr Opin Pharmacol 1:459-63, 2001.

60. Nightingale $\mathrm{CH}$. Moxifloxacin, a new antibiotic designed to treat community-acquired respiratory tract infections: a review of microbiologic and pharmacokinetic-pharmacodynamic characteristics. Pharmacother 20:245-56, 2000.

61. Klugman KP, Capper T. Concentration-dependent killing of antibiotic-resistant pneumococci by the methoxyquinolone moxifloxacin. J Antimicrob Chemother 40:797-802, 1997.

62. Boswell FJ, Andrews JM, Wise R, et al. Bactericidal properties of moxifloxacin and post-antibiotic effect. J Antimicrob Chemother 43 Suppl B:43-9, 1999.

63. Maggiolo F, Capra R, Bartoli A, et al. Effects of subinhibitory concentrations of moxifloxacin in an in-vitro dynamic model. J Chemother 12:129-33, 2000.

64. Schentag JJ. Pharmacokinetic and pharmacodynamic predictors of antimicrobial efficacy: moxifloxacin and Streptococcus pneumoniae. J Chemother 14 Suppl 2:13-21, 2002.

65. Berrington AW, Perry JD, Gould FK. Bactericidal activity of moxifloxacin against Staphylococcus aureus. Clin Microbiol Infect 7:161-3, 2001.

66. Wright DH, Gunderson BW, Hovde LB, et al. Comparative pharmacodynamics of three newer fluoroquinolones versus six strains of staphylococci in an in vitro model under aerobic and anaerobic conditions. Antimicrob Agents Chemother 46:1561-3, 2002.

67. MacGowan AP, Bowker KE, Wootton M, et al. Activity of moxifloxacin, administered once a day, against Streptococcus pneumoniae in an in vitro pharmacodynamic model of infection. Antimicrob Agents Chemother 43:1560-4, 1999.

68. Esposito S, Noviello S, Ianniello F. Bactericidal activity of moxifloxacin compared to grepafloxacin and clarithromycin against Streptococcus pneumoniae and Streptococcus pyogenes investigated using an in vitro pharmacodynamic model. J Chemother 12:475-81, 2000.

69. Klepser ME, Ernst EJ, Petzold CR, et al. Comparative bactericidal activities of ciprofloxacin, clinafloxacin, grepafloxacin, levofloxacin, moxifloxacin, and trovafloxacin against Streptococcus pneumoniae in a dynamic in vitro model. Antimicrob Agents Chemother 45:673-8, 2001.

70. Lister PD, Sanders CC. Pharmacodynamics of moxifloxacin, levofloxacin and sparfloxacin against Streptococcus pneumoniae. J Antimicrob Chemother 47:811-8, 2001.

71. Levy D, Berche P. Bactericidal activity of moxifloxacin against pneumococci. Clin Microbiol Infect 7:47-8, 2001.

72. Zhanel GG, Roberts D, Waltky A, et al. Pharmacodynamic activity of fluoroquinolones against ciprofloxacinresistant Streptococcus pneumoniae. J Antimicrob Chemother 49:807-12, 2002.

73. Firsov AA, Lubenko IY, Vostrov SN, et al. Comparative pharmacodynamics of moxifloxacin and levofloxacin in an in vitro dynamic model: prediction of the equivalent AUC/MIC breakpoints and equiefficient doses. J Antimicrob Chemother 46:725-32, 2000. 
74. Firsov AA, Zinner SH, Vostrov SN, et al. AUC/MIC relationships to different endpoints of the antimicrobial effect: multiple-dose in vitro simulations with moxifloxacin and levofloxacin. J Antimicrob Chemother 50:533-9, 2002.

75. Stass H, Dalhoff A, Kubitza D, et al. Pharmacokinetics, safety, and tolerability of ascending single doses of moxifloxacin, a new 8-methoxy quinolone, administered to healthy subjects. Antimicrob Agents Chemother 42:2060$5,1998$.

76. Ballow C, Lettieri J, Agarwal V, et al. Absolute bioavailability of moxifloxacin. Clin Therap 21:513-22, 1999.

77. Stass H, Kubitza D. Pharmacokinetics and elimination of moxifloxacin after oral and intravenous administration in man. J Antimicrob Chemother 43 Suppl B:83-90, 1999.

78. Lettieri J, Vargas R, Agarwal V, et al. Effect of food on the pharmacokinetics of a single oral dose of moxifloxacin 400mg in healthy male volunteers. Clin Pharmacokin 40 Suppl 1:19-25, 2001.

79. Stass H, Kubitza D. Effects of dairy products on the oral bioavailability of moxifloxacin, a novel 8methoxyfluoroquinolone, in healthy volunteers. Clin Pharmacokin 40 Suppl 1:33-8, 2001.

80. Stass H, Wandel C, Delesen H, et al. Effect of calcium supplements on the oral bioavailability of moxifloxacin in healthy male volunteers. Clin Pharmacokin 40 Suppl 1:27-32, 2001.

81. Lubasch A, Keller I, Borner K, et al. Comparative pharmacokinetics of ciprofloxacin, gatifloxacin, grepafloxacin, levofloxacin, trovafloxacin, and moxifloxacin after single oral administration in healthy volunteers. Antimicrob Agents Chemother 44:2600-3, 2000.

82. Stass H, Kubitza D, Schuhly U. Pharmacokinetics, safety and tolerability of moxifloxacin, a novel 8methoxyfluoroquinolone, after repeated oral administration. Clin Pharmacokin 40 Suppl 1:1-9, 2001.

83. Sullivan JT, Lettieri JT, Liu P, et al. The influence of age and gender on the pharmacokinetics of moxifloxacin. Clin Pharmacokin 40 Suppl 1:11-8, 2001.

84. Stass H, Kubitza D, Halabi A, et al. Pharmacokinetics of moxifloxacin, a novel 8-methoxy-quinolone, in patients with renal dysfunction. Br J Clin Pharmacol 53:232-7, 2002.

85. Wise R, Andrews JM, Marshall G, et al. Pharmacokinetics and inflammatory-fluid penetration of moxifloxacin following oral or intravenous administration. Antimicrob Agents Chemother 43:1508-10, 1999.

86. Muller M, Stass H, Brunner M, et al. Penetration of moxifloxacin into peripheral compartments in humans. Antimicrob Agents Chemother 43:2345-9, 1999.

87. Soman A, Honeybourne D, Andrews J, et al. Concentrations of moxifloxacin in serum and pulmonary compartments following a single $400 \mathrm{mg}$ oral dose in patients undergoing fibre-optic bronchoscopy. J Antimicrob Chemother 44:835-8, 1999.

88. Gehanno P, Darantiere S, Dubreuil C, et al. A prospective, multicentre study of moxifloxacin concentrations in the sinus mucosa tissue of patients undergoing elective surgery of the sinus. J Antimicrob Chemother 49:821-6, 2002.

89. Pascual A, Garcia I, Ballesta S, et al. Uptake and intracellular activity of moxifloxacin in human neutrophils and tissue-cultured epithelial cells. Antimicrob Agents Chemother 43:12-5, 1999.

90. Mandell GL, Coleman E. Uptake, transport, and delivery of antimicrobial agents by human polymorphonuclear neutrophils. Antimicrob Agents Chemother 45:1794-8, 2001.

91. Stass H, Bottcher MF, Ochmann K. Evaluation of the influence of antacids and H2 antagonists on the absorption of moxifloxacin after oral administration of a 400mg dose to healthy volunteers. Clin Pharmacokin 40 Suppl 1:39$48,2001$.

92. Stass H, Schuhly U, Moller JG, et al. Effects of sucralfate on the oral bioavailability of moxifloxacin, a novel 8methoxyfluoroquinolone, in healthy volunteers. Clin Pharmacokin 40 Suppl 1:49-55, 2001.

93. Stass H, Kubitza D. Effects of iron supplements on the oral bioavailability of moxifloxacin, a novel 8methoxyfluoroquinolone, in humans. Clin Pharmacokin 40 Suppl 1:57-62, 2001.

94. Stass H, Kubitza D. Lack of pharmacokinetic interaction between moxifloxacin, a novel 8methoxyfluoroquinolone, and theophylline. Clin Pharmacokin 40 Suppl 1:63-70, 2001.

95. Stass H, Sachse R. Effect of probenecid on the kinetics of a single oral 400mg dose of moxifloxacin in healthy male volunteers. Clin Pharmacokin 40 Suppl 1:71-6, 2001.

96. Stass H, Kubitza D. Profile of moxifloxacin drug interactions. Clin Infect Dis 32 Suppl 1:S47-50, 2001.

97. Lode H. Evidence of different profiles of side effects and drug-drug interactions among the quinolones-the pharmacokinetic standpoint. Chemother 47 Suppl 3:24-31; 2001. 
98. Talan DA. Clinical perspectives on new antimicrobials: focus on fluoroquinolones. Clin Infect Dis 32 Suppl 1:S64-71, 2001.

99. Lode H, Garau J. Improving care for patients with respiratory tract infections. J Chemother 14 Suppl 2:22-8, 2002.

100. Appelbaum PC. Resistance among Streptococcus pneumoniae: Implications for drug selection. Clin Infect Dis 34:1613-20, 2002.

101. Fogarty C, Grossman C, Williams J, et al. Efficacy and safety of moxifloxacin vs clarithromycin for communityacquired pneumonia. Infect Med 16: 748-763, 1999

102. Hoeffken G, Meyer HP, Winter J, et al. The efficacy and safety of two oral moxifloxacin regimens compared to oral clarithromycin in the treatment of community-acquired pneumonia. Resp Med 95:553-64, 2001.

103. Petitpretz P, Arvis P, Marel M, et al. Oral moxifloxacin vs high-dosage amoxicillin in the treatment of mild-tomoderate, community-acquired, suspected pneumococcal pneumonia in adults. Chest 119:185-95, 2001.

104. Finch R, Schurmann D, Collins O, et al. Randomized controlled trial of sequential intravenous (i.v.) and oral moxifloxacin compared with sequential i.v. and oral co-amoxiclav with or without clarithromycin in patients with community-acquired pneumonia requiring initial parenteral treatment. Antimicrob Agents Chemother 46:1746-54, 2002.

105. Patel T, Pearl J, Williams J, et al. Efficacy and safety of ten day moxifloxacin $400 \mathrm{mg}$ once daily in the treatment of patients with community-acquired pneumonia. Community Acquired Pneumonia Study Group. Resp Med 94:97105, 2000.

106. Landen H, Moller M, Tillotson GS, et al. Clinical experience in Germany of treating community-acquired respiratory infections with the new 8-methoxyfluoroquinolone, moxifloxacin. J Int Med Res 29:51-60, 2001.

107. Chodosh S, DeAbate CA, Haverstock D, et al. Short-course moxifloxacin therapy for treatment of acute bacterial exacerbations of chronic bronchitis. The Bronchitis Study Group. Resp Med 94:18-27, 2000.

108. Wilson R, Kubin R, Ballin I, et al. Five day moxifloxacin therapy compared with 7 day clarithromycin therapy for the treatment of acute exacerbations of chronic bronchitis. J Antimicrob Chemother 44:501-13, 1999.

109. DeAbate CA, Mathew CP, Warner JH, et al. The safety and efficacy of short course (5-day) moxifloxacin vs. azithromycin in the treatment of patients with acute exacerbation of chronic bronchitis. Resp Med 94:1029-37, 2000.

110. Schaberg T, Ballin I, Huchon G, et al. The AECB Study Group. A multinational, multicentre, non-blinded, randomized study of moxifloxacin oral tablets compared with co-amoxiclav oral tablets in the treatment of acute exacerbation of chronic bronchitis. J Int Med Res 29:314-28, 2001.

111. Grassi C, Casali L, Curti E, et al. Efficacia e tollerabilità di un trattamento a breve termine (5 giorni) con moxifloxacina verso una terapia di 7 giorni con ceftriaxone della bronchite cronica riacutizzata (AECB).J Chemother 14: 543-554, 2002.

112. Lorenz J, Busch W, Thate-Waschke IM, et al. BRONCHIMOX Study Group. Moxifloxacin in acute exacerbations of chronic bronchitis: clinical evaluation and assessment by patients. J Int Med Res 29:61-73, 2001.

113. Lorenz J, Thate-Waschke IM, Mast O, et al. Treatment outcomes in acute exacerbations of chronic bronchitis: comparison of macrolides and moxifloxacin from the patient perspective. J Int Med Res 29:74-86, 2001.

114. Miravitlles M, Ros F, Cobos A, et al. The efficacy of moxifloxacin in acute exacerbations of chronic bronchitis: a Spanish physician and patient experience. Int J Clin Pract 55:437-41, 2001.

115. Burke T, Villanueva C, Mariano H Jr, et al. Comparison of moxifloxacin and cefuroxime axetil in the treatment of acute maxillary sinusitis. Sinusitis Infection Study Group. Clin Ther 21:1664-77, 1999.

116. Siegert R, Gehanno P, Nikolaidis P, et al. A comparison of the safety and efficacy of moxifloxacin (BAY 12-8039) and cefuroxime axetil in the treatment of acute bacterial sinusitis in adults. The Sinusitis Study Group. Resp Med 94:337-44, 2000.

117. Rakkar S, Roberts K, Towe BF, et al. Moxifloxacin versus amoxicillin clavulanate in the treatment of acute maxillary sinusitis: a primary care experience. Int J Clin Pract 55:309-15, 2001.

118. Klossek JM, Siegert R, Nikolaidis P, et al. Sinusitis Study Group. Comparison of the efficacy and safety of moxifloxacin and trovafloxacin for the treatment of acute, bacterial maxillary sinusitis in adults. J Laryngol Otol 117:43-51, 2003.

119. Iannini PB, Kubin R, Reiter C, et al. Reassuring safety profile of moxifloxacin. Clin Infect Dis 32:1112-4, 2001. 
120. Iannini PB, Mandell LA. An updated safety profile of moxifloxacin. J Chemother 14 Suppl 2:29-34, 2002.

121. Man I, Murphy J, Ferguson J. Fluoroquinolone phototoxicity: a comparison of moxifloxacin and lomefloxacin in normal volunteers. J Antimicrob Chemother 43 Suppl B:77-82, 1999.

122. Jeffrey AM, Shao L, Brendler-Schwaab SY, et al. Photochemical mutagenicity of phototoxic and photochemically carcinogenic fluoroquinolones in comparison with the photostable moxifloxacin. Arch Toxicol 74:555-9, 2000.

123. Schmuck G, Schurmann A, Schluter G. Determination of the excitatory potencies offluoroquinolones in the central nervous system by an in vitro model. Antimicrob Agents Chemother 42:1831-6, 1998.

124. Demolis JL, Kubitza D, Tenneze L, et al. Effect of a single oral dose of moxifloxacin (400 $\mathrm{mg}$ and $800 \mathrm{mg}$ ) on ventricular repolarization in healthy subjects. Clin Pharmacol Therap 68:658-66, 2000.

125. Kang J, Wang L, Chen XL, et al. Interactions of a series of fluoroquinolone antibacterial drugs with the human cardiac K+ channel HERG. Mol Pharmacol 59:122-6, 2001.

126. Siepmann M, Kirch W. Drug Points: tachycardia associated with moxifloxacin. BMJ. 322(7277):23, 2001.

127. White CM, Grant EM, Quintiliani R. Moxifloxacin does increase the corrected QT interval. Clin Infect Dis 33:14414, 2001.

128. Frothingham R. Rates of torsades de pointes associated with ciprofloxacin, ofloxacin, levofloxacin, gatifloxacin, and moxifloxacin. Pharmacother 21:1468-72, 2001.

129. Owens RC Jr, Ambrose PG. Torsades de pointes associated with fluoroquinolones. Pharmacother 22:663-8; 2002.

130. Leone R, Venegoni M, Motola D, et al. Adverse drug reactions related to the use of fluoroquinolone antimicrobials: an analysis of spontaneous reports and fluoroquinolone consumption data from three italian regions. Drug Saf 26:109-20, 2003.

131. Li-McLeod J, Perfetto EM. Workplace costs associated with acute exacerbation of chronic bronchitis: a comparison of moxifloxacin and levofloxacin. Managed Care Interf 14:52-9, 2001. 